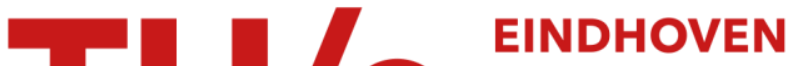 UNIVERSITY OF TECHNOLOGY
}

\section{Effect of the Helix-Coil transition in Bovine skin gelatin on its associative phase separation with Lysozyme}

Citation for published version (APA):

Antonov, Y. A., Zhuravleva, I. L., Volodine, A., Moldenaers, P., \& Cardinaels, R. M. (2017). Effect of the HelixCoil transition in Bovine skin gelatin on its associative phase separation with Lysozyme. Langmuir, 33(47), 13530-13542. https://doi.org/10.1021/acs.langmuir.7b01477

DOI:

10.1021/acs.langmuir.7b01477

Document status and date:

Published: 13/11/2017

Document Version:

Accepted manuscript including changes made at the peer-review stage

Please check the document version of this publication:

- A submitted manuscript is the version of the article upon submission and before peer-review. There can be important differences between the submitted version and the official published version of record. People interested in the research are advised to contact the author for the final version of the publication, or visit the $\mathrm{DOI}$ to the publisher's website.

- The final author version and the galley proof are versions of the publication after peer review.

- The final published version features the final layout of the paper including the volume, issue and page numbers.

Link to publication

\section{General rights}

Copyright and moral rights for the publications made accessible in the public portal are retained by the authors and/or other copyright owners and it is a condition of accessing publications that users recognise and abide by the legal requirements associated with these rights.

- Users may download and print one copy of any publication from the public portal for the purpose of private study or research.

- You may not further distribute the material or use it for any profit-making activity or commercial gain

- You may freely distribute the URL identifying the publication in the public portal.

If the publication is distributed under the terms of Article 25fa of the Dutch Copyright Act, indicated by the "Taverne" license above, please follow below link for the End User Agreement:

www.tue.nl/taverne

Take down policy

If you believe that this document breaches copyright please contact us at:

openaccess@tue.nl

providing details and we will investigate your claim. 


\title{
Effect of the Helix-Coil Transition in Bovine Skin Gelatin on Its Associative Phase
}

\section{Separation With Lysozyme}

Yurij A. Antonov ${ }^{\mathrm{a} *}$, Irina Zhuravleva ${ }^{\mathrm{a}}$, Aleksander Volodine ${ }^{\mathrm{b}}$, Paula Moldenaers ${ }^{\mathrm{c}}$ \& Ruth

Cardinaels ${ }^{\mathrm{c}, \mathrm{d}}$

${ }^{a}$ N.M. Emanuel Institute of Biochemical Physics, Russian Academy of Sciences, Kosygin Str. 4., 119334 Moscow, Russia

${ }^{b}$ Laboratory of Solid State Physics and Magnetism, Department of Physics and Astronomy, Celestijnenlaan 200D, Box 2414, B-3001 Leuven, Belgium

${ }^{c}$ Soft Matter Rheology and Technology, Department of Chemical Engineering, KU Leuven, Celestijnenlaan 200f, Box 2424, B-3001 Leuven, Belgium

${ }^{d}$ Polymer Technology, Department of Mechanical Engineering, TU Eindhoven, Box 513, 5600 $M B$ Eindhoven, The Netherlands

*Corresponding author: Yurij Antonov, e-mail: chehonter@yandex.ru

\begin{abstract}
It is known that the formation of electrostatic polyelectrolyte complexes can induce conformational changes of the interacting macromolecules. However, the opposite effect namely that of the helix-coil transition of one of the interacting polyelectrolytes on its associative phase separation with another polyelectrolyte and the possible phase transitions in such systems have not been determined. Atomic force and confocal laser scanning microscopy, phase analysis, dynamic and electrophoretic light scattering, turbidimetry, absorption and fluorescence measurements as well as differential scanning calorimetry and rheology were used to study the effect of the helixcoil transition in bovine skin gelatin $(\mathrm{Gel})$ on its associative phase separation with hen egg white lysozyme (Lys) at different temperatures $\left(18^{\circ} \mathrm{C}-40^{\circ} \mathrm{C}\right)$ and various Lys/Gel weight ratios $(0.01-$ $100)$ at low ionic strength (0.01) and $\mathrm{pH}$ 7.0. The effects of the main variables on the phase state, phase diagram, the main complexation and binding parameters, as well as the temperature and enthalpy of the helix-coil transition of Gel within the complexes were investigated. Associative phase separation is only observed for the system with Gel in the helix state. Effective charge, structure, the solution and rheological behavior of the formed complexes proved to be dependent on the $\left[\mathrm{An}^{-}\right] /\left[\mathrm{Cat}^{+}\right]$charge ratio. Localisation of Lys within the complex particles has an irregular character without formation of a single center of binding. Binding of Lys with Gel does not lead to disruption of its tertiary structure nor to an appreciable change in the thermodynamic parameters of the thermal transitions of Lys. Gel in the coil state only interacts weakly with Lys forming water soluble complex associates. It is suggested that the Voorn-Overbeek model could potentially describe the stronger binding and phase separation in the case of Gel in the helix state.
\end{abstract}

Keywords: Lysozyme, gelatin, associative phase separation, helix-coil transition, structure

\section{INTRODUCTION}

Proteins can interact with synthetic and biological polyelectrolytes (PE), polyampholytes and other proteins forming macromolecular complexes. The interactions and resulting complex formation in 
such systems have a global importance in living systems due to their key role in the synthesis of proteins in cellular systems ${ }^{1}$ and in the maintenance of homeostasis in living cells. ${ }^{2,3}$ Since interactions in protein-protein systems are frequently accompanied by phase separation and change of structure, unique physico-chemical properties can be generated. ${ }^{4-8}$ Therefore, understanding the interactions between two proteins as well as between a protein and a PE is essential not only because of its biological significance ${ }^{9,10}$ but also because it paves the path for a wide range of applications. ${ }^{11-19}$ The main distinctions between the interactions of two proteins and that of two PE molecules are the differences in their interaction force ${ }^{20}$ and the disposition of the oppositely charged functional groups of protein-protein systems. ${ }^{20,21}$ Usually, the interaction force between two proteins is relatively low and does not significantly exceed the thermal energy $k T$. Therefore two macroions with opposite charges can arrange themselves in the optimal orientation with respect to each other for the best binding. ${ }^{20}$ However, due to the difference in structure of proteins and polyelectrolytes and the location and density of their functional groups, the distance between interacting ionogenic groups in protein molecules is in general larger than in polyelectrolytes. This hampers total charge neutralization during binding of two proteins. ${ }^{21}$ Interactions of several globular proteins have recently been studied. ${ }^{4-8,21-26}$ It was shown that linear and fibrillary macromolecular complexes are formed under conditions favorable for electrostatic repulsions of the biopolymers (i.e. far from the isoelectric point). On the other hand, spherical complexes are typical for conditions of strong electrostatic interactions. $^{21,26}$ It was proposed that in contrast to protein-polyelectrolyte systems complex coacervation (liquid-liquid phase separation) in protein-protein systems can only be observed as a result of a precise balance of repulsive and attractive forces. ${ }^{8}$ This can be attributed to the fact that the structural homogeneity of protein complexes substantially limits the entropy of coacervation in such systems.

The effect of helix-coil conformational changes in interacting protein systems on phase separation and possible phase transitions in such systems is relatively unexplored. Experimental data in this field are almost absent. We can only refer to our previous study on the complexation of BSA with gelatin in which it was shown that the conformation of the gelatin molecules is an important factor affecting the interaction of these proteins. ${ }^{27}$

Lysozyme (Lys) is a small $(14.3 \mathrm{kDa})$ globular protein that is characterized by a high enzymatic activity. Lys was chosen for this study because it is one of the main basic proteins which exhibits a simple two-state thermodenaturation behavior in aqueous medium. ${ }^{28}$ Gelatins (Gel) are high molecular weight polypeptides derived from collagen, the primary protein component of animal connective tissues, such as bone, skin and tendon that is widely used in food industries. Molecules of Gel are very unusual because they consist out of triplets of aminoacids containing mainly glycine, proline and 4-hydroxyproline. The last two aminoacids have a five member ring structure. 
The polyampholyte properties, conformational transitions and gel formation of Gel solutions have been studied in the past. ${ }^{29}$ Gel in mixtures with globular proteins are frequently used in pharmaceutics and for controlled release. ${ }^{30}$

In the present work we examine whether the interaction of the alkaline globular protein (Lys) with gelatin type B leads to phase transitions during the helix-coil conformational changes of gelatin, we determine the key parameters of the complexation ( $\mathrm{q}_{\text {Onset, }} \mathrm{q}_{\phi}$ and $\mathrm{q}_{\mathrm{Max}}$ ), and the binding constants at different conformation states of gelatin, as well as the localization of both biopolymers within the complex particles at various compositions of the system. Thereto phase analysis, turbidity measurements, dynamic light scattering (DLS), confocal laser scanning (CLSM) and atomic force microscopy (AFM), absorption and fluorescence spectroscopy, electrophoretic mobility studies, differential scanning microcalorimetry (DSMC) and rheology are utilized. The binding of Lys to Gel is in qualitative agreement with a model for interaction of small ligands with a large macromolecule. The thermodynamic binding parameters for Gel in the helix and coil states are evaluated.

\section{EXPERIMENTAL SECTION}

\subsection{Materials.}

Proteins and reagents. Highly purified Lys from chicken egg white (dialyzed, lyophilized powder) $\geq 96 \%$ (SDS-PAGE) with $0.4 \%$ ash was purchased from Sigma-Aldrich and used without further purification. The gelatin (Gel) sample used is Gel from bovine skin type B 230 Bloom PS 8/30 produced by Sigma Chemical Co. The protein content, Bloom number, and isoelectric point of the sample, as reported by the manufacturer, are, respectively, 86.6\%, 230, and 5.4. The gelatin sample had a slightly yellow colour, contained traces of peptides $(0.1 \%)$, and a small amount of mineral substances $(0.46 \%$ ash). Milli-Q ultrapure water was used in all experiments. Most experiments were performed in a dilute mono/bisphosphate $\left(\mathrm{KH}_{2} \mathrm{PO}_{4}+\mathrm{K}_{2} \mathrm{HPO}_{4}\right)$ buffer with $I=0.01$.

Preparation of the protein solutions and protein/protein mixtures. Lys solutions were prepared by dispersing Lys in mono/bisphosphate $\left(\mathrm{KH}_{2} \mathrm{PO}_{4}+\mathrm{K}_{2} \mathrm{HPO}_{4}\right)$ buffer with $I=0.01$ and stirring at room temperature for $1 \mathrm{~h}$. Molecularly dispersed solutions comprising of gelatin in the coil state $(\mathrm{Gel})$ were prepared by dispersing gelatin in mono/bisphosphate $\left(\mathrm{KH}_{2} \mathrm{PO}_{4}+\mathrm{K}_{2} \mathrm{HPO}_{4}\right)$ buffer with $I=0.01$ and stirring at $20^{\circ} \mathrm{C}$ for $40 \mathrm{~min}$ to allow swelling of the gelatin particles, followed by stirring at $60^{\circ} \mathrm{C}$ for $20 \mathrm{~min}$ to remove any possible prehistory, and finally stirring at $40^{\circ} \mathrm{C}$ for $1 \mathrm{~h}$. Solutions of gelatin associates (GelA), containing gelatin in the ordered state were produced on the basis of the procedure described by Boedtker \& Doty ${ }^{31}$, which we 
modified to obtain completely stable solutions during long time storage. Thereto, Gel solutions were prepared as described above, stored at $5^{\circ} \mathrm{C}$ overnight, and then placed in a thermostated bath at $18^{\circ} \mathrm{C}$ for $8 \mathrm{~h}$. After preparation, the protein solutions were subjected to centrifugation to remove insoluble aggregates, using $50000 \mathrm{~g}$ for $1 \mathrm{~h}$ at $20^{\circ} \mathrm{C}$ for Lys, $50000 \mathrm{~g}$ for $1 \mathrm{~h}$ at $40^{\circ} \mathrm{C}$ for $\mathrm{Gel}$ and $20000 \mathrm{~g}$ for $30 \mathrm{~min}$ at $18^{\circ} \mathrm{C}$ for GelA. The final solutions of GelA were optically transparent and stable against aggregation during experiments at $18^{\circ} \mathrm{C}$ and during storage for one month at $4{ }^{\circ} \mathrm{C}$. The average radius of the particles in the GelA solution was $270 \mathrm{~nm}$, which is 2.2 times larger than that of Gel in the coil state. The viscosity average molecular weight $\mathrm{M}_{\eta}$ values of $\mathrm{Gel}$ at $40^{\circ} \mathrm{C}(87 \mathrm{kDa})$ and $\mathrm{GelA}$ at $20^{\circ} \mathrm{C}(3000 \mathrm{kDa})$ were determined from the intrinsic viscosity using the Mark-Houwink parameters for gelatin at $40^{\circ} \mathrm{C}^{32}$ and $20^{\circ} \mathrm{C}^{33}$.

The Lys content in the stock solution was determined by means of UV absorption using the extinction coefficient for highly purified Lys in $0.1 \mathrm{M}$ potassium chloride at $281.5 \mathrm{~nm}$ which is $2.64 \mathrm{ml} \mathrm{mg}^{-1} \mathrm{~cm}^{-1} \cdot{ }^{34}$ Concentrations of Gel and GelA in the solutions and the coexisting phases in the complex mixtures were determined by drying at $104^{\circ} \mathrm{C}$ up to constant weight, taking into account the protein content in the samples.

For all solutions, the required $\mathrm{pH}$ value (7.0) was obtained by addition of $0.1-0.25 \mathrm{M} \mathrm{NaOH}$ or $\mathrm{HCl}$. To prepare mixed solutions of Lys and Gel or Lys and GelA with the required concentrations, weighed amounts of the Lys stock solution were added to a Gel or GelA solution and subsequently the mixtures were stirred for $2 \mathrm{~h}$ at $18^{\circ} \mathrm{C}$ in the case of Lys/GelA and at $40^{\circ} \mathrm{C}$ for Lys/Gel.

\subsection{Methods.}

2.2.1. Turbidimetry. Determination of $q_{\text {Onset }}, q_{\phi}, q_{\operatorname{Max}}, q^{*}$, and $q_{\text {Set. }}$ The main parameters of the complexation process were determined by measuring the turbidity at $500 \mathrm{~nm}\left(\tau_{500}\right)$ for Lys/GelA mixtures as function of the Lys/GelA weight ratio (q) using a JASCO V-630 spectrophotometer. The error of the turbidity measurements is typically about $2 \%-3 \%$, only in the charge ratio range from 0.7 to 2.6 , the errors are markedly larger (6-8\%). Usually the dependence on the relative protein composition is characterized by specific $q$ values corresponding to transitions from the absence of complexation to formation of water soluble complexes (qOnset), from water soluble complexes to water insoluble complexes and their phase separation $\left(\mathrm{q}_{\phi}\right)$, maximal complexation $\left(\mathrm{q}_{\max }\right)$, transition from formation of water insoluble complexes to water soluble complexes $\left.\left(\mathrm{q}^{*}\right)\right)$, and again the absence of complexation $\left(\mathrm{q}_{\mathrm{Set}}\right) .{ }^{35}$ Time dependent measurements allowed to assess the presence of phase separation and thus to determine $\mathrm{q}_{\phi}$ and $\mathrm{q}^{*}{ }_{\phi}$ whereas qonset and qset were characterized by the presence of large aggregates, as described in detail in our recent work. ${ }^{36}$ Temperatures for the transition from formation of water insoluble complexes to water soluble complexes $\left(\mathrm{T}^{*} \phi\right)$ and the absence of complexation $\left(\mathrm{T}_{\mathrm{set}}\right)$ are determined in a similar way. 
2.2.2. Electrophoretic Mobility. $\varsigma$-potential measurements of Lys, Gel, GelA, and the complexes of Gel or GelA with Lys at different Lys/Gel and Lys/GelA weight ratios (q) were performed at $18^{\circ} \mathrm{C}$ and $40^{\circ} \mathrm{C}$ with a 90 Plus particle size analyzer (Brookhaven instruments Inc.) using a rectangular quartz capillary cell. For each sample the $\varsigma$-potential was determined at least ten times and the average value is reported.

2.2.3. Phase analysis. The yields of the macromolecular components in the coexistence phases were determined by measuring the masses of the complex phase and the supernatant, and the total concentrations of biopolymers in these phases after centrifugation and subsequent separation of the phases. First, the total concentrations of GelA and Lys in the complex phase and the supernatant were determined by measuring the dry weight residue, after subtraction of the dry weight of the solvent (phosphate buffer, $I=0.01$ ). The experimental errors were 2-3\%. Subsequently, the Lys content in the complex phase was determined by means of UV absorption at $281.5 \mathrm{~nm}$ after solubilisation of the complex precipitate in the presence of $0.5 \mathrm{M} \mathrm{NaCl}$. The concentration of Lys in the supernatant was calculated from the total amount of Lys introduced in the Lys/GelA mixture and the amount of Lys found in the complex phase. Finally, the concentrations of GelA in the coexisting phases of the Lys/GelA mixtures were established by subtracting the concentration of Lys in each phase from the total concentration of biopolymers in this phase. The experimental error on the GelA content was approximately 8-10\%.

2.2.4. Light Scattering. Determination of the intensity and number size distribution functions of the complexes in Lys/GelA mixtures was performed with an ALV/CGS-3 compact goniometer system (ALV GmbH, Germany) at $18^{\circ} \mathrm{C}$. The system is equipped with an ALV-5000/EPP multi tau digital correlator, a HeNe laser operating at a wavelength of $632.8 \mathrm{~nm}$, and an avalanche photodiode detector. The refractive index used in the ALV/CGS-3 compact goniometer to convert the complex signal intensity to the number size distribution was 1.332. The Lys solutions were filtered through $0.22 \mu \mathrm{m}$ DISMIC-25cs (cellulose acetate) filters (Millipore) to remove dust particles. Samples of the Lys/GelA system were used without filtration. All samples were centrifuged for $30 \mathrm{~s}$ at $2000 \mathrm{~g}$ to remove air bubbles. The detected scattering light intensity was processed by digital ALV-5000 Correlator software. To process the DLS data the cumulant method was used. For each sample the measurement was repeated three times.

2.2.5. Fluorescent imaging. Imaging was performed with a multi-beam confocal microscope (VisiTech, UK), equipped with an oil-immersion objective (x20, 0.85 NA, Olympus, Japan) using $532 \mathrm{~nm}$ and $642 \mathrm{~nm}$ as excitation wavelengths. GelA and Lys were fluorescently labeled before imaging by storing GelA and Lys solutions containing respectively Rhodamine B dye 
or Atto $647 \mathrm{~N}$ dye (ATTO Tec. Germany) for one day at $5^{\circ} \mathrm{C}$. This labeling allowed to spectrally separate the signal from GelA (green) and Lys (orange).

2.2.6. Fluorescence spectroscopy. Fluorescence emission spectra between $300 \mathrm{~nm}$ and $450 \mathrm{~nm}$ were recorded on an RF 5301 PC Spectrofluorimeter (Shimadzu, Japan) at $18^{\circ} \mathrm{C}$ and $40^{\circ} \mathrm{C}$ with the excitation wavelength set to $280 \mathrm{~nm}$, slit widths of $3 \mathrm{~nm}$ for both excitation and emission, and an integration time of $0.5 \mathrm{~s}$. The fluorescence intensity was corrected for absorption of excited light and re-absorption of emitted light to decrease the inner filter effect using the relationship: ${ }^{37}$

$$
F_{c o r}=F_{o b s} \times \exp \left(\frac{A_{e x}+A_{e m}}{2188}\right)
$$

where $F_{c o r}$ and $F_{o b s}$ are the corrected and observed fluorescence intensities respectively, and $A_{e x}$ and $A_{e m}$ are the absorptions of the systems at the excitation and the emission wavelength, respectively. The reported intensity values are the corrected fluorescence intensities. The experimental errors were approximately $2 \%$.

\subsubsection{Rheological measurements. Dynamic moduli were determined with an Anton Paar MCR501} rheometer with a cone-plate geometry with $50 \mathrm{~mm}$ diameter and a cone angle of $1^{\circ}$. The temperature was controlled at $18^{\circ} \mathrm{C}$ using a Peltier element. Frequency sweeps in the range of $0.1-$ $100 \mathrm{rad} / \mathrm{s}$ were carried out with a strain of $3.0 \%$, which is in the linear response regime. During the rheological measurements, the edges of the samples were covered with paraffin oil to avoid drying.

2.2.8. Atomic force microscopy. For the determination of the surface morphology solutions of Gel, GelA and their mixtures with Lys at desirable concentrations were subjected to complete drying at $18^{\circ} \mathrm{C}\left(\mathrm{GelA}\right.$, Lys/GelA systems) or at $40^{\circ} \mathrm{C}$ (Gel, Lys/Gel systems) using graphene plates. The surface morphology of the dried samples was measured with an Agilent 5500 atomic force microscope (AFM) operated in tapping mode at ambient conditions (relative humidity 30\%). Commercial AFM cantilevers (PPP-NCSTR AFM probes from NanoAndMore GmbH) made of Si with a nominal spring constant of $7.4 \mathrm{Nm}^{-1}$ and with a typical tip radius of less than $7 \mathrm{~nm}$ were used. AFM measurements were performed with scan areas of $0.5 \times 0.5 \mu \mathrm{m}^{2}$ and $5 \times 5 \mu \mathrm{m}^{2}$ at different locations for each of the samples.

2.2.9. High-Sensitivity DSMC. Thermal denaturation of Lys in an aqueous solution in the absence and in the presence of GelA was monitored with a highly sensitive differential scanning calorimeter (DASM-4 M, Puschino, Russia). Thermograms were obtained between $10^{\circ} \mathrm{C}$ and $90^{\circ} \mathrm{C}$, at a scan rate of $120^{\circ} \mathrm{C} / \mathrm{h}$. Degassing during the calorimetric experiments was prevented by an additional constant pressure of $172.25 \mathrm{kPa}$ applied over the liquids in the cells. The denaturation 
enthalpy was determined as the area of the heat capacity peak over a baseline, while the effective enthalpy of denaturation was obtained using the van't Hoff equation. ${ }^{38}$

\section{RESULTS AND DISCUSSION}

\subsection{Gelatin in ordered helix conformation.}

\subsubsection{Turbidimetry. Determination of $q_{\text {Onset }}, q_{\phi}, q_{M a x}, q^{*} \phi$ and $q_{\text {Set. }}$}

Turbidimetry was used to map out the complexation process as a function of Lys/GelA weight ratio and mixing conditions in a phosphate buffer at $\mathrm{pH} 7.0$ and ionic strength $I=0.01$ as both former parameters are expected to affect the formation and solubility of Lys/GelA complexes. Mixing transparent solutions of Lys and GelA leads to a quick appearance of turbidity in the mixtures if the Lys/GelA weight ratio (q) exceeds the qonset value. The turbidity values of the complex mixtures and the average size of the complex particles reached a steady state value after 10 min of mixing (data not presented). Therefore, a large series of mixed solutions ( $>50)$ differing in $q$ value were analyzed by means of spectrophotometry in the visible wavelength range after mixing at $18^{\circ} \mathrm{C}$ during $20 \mathrm{~min}$. Figure 1 a shows the turbidity values at $500 \mathrm{~nm}\left(\tau_{500}\right)$ as a function of $\mathrm{q}$ for complex mixtures with a total concentration of Lys plus GelA of $0.12 \mathrm{wt} \%$. As can be seen in Figure 1a, the $\tau_{500}$ values of the complex mixtures are much higher than the corresponding values for the pure component solutions which confirms the presence of complexation. The mixture behavior clearly depends on the Lys/GelA weight ratio (q), with $\tau_{500}$ exhibiting a maximum at $\mathrm{q}=1.47$. The Lys/GelA molar ratio corresponding to this $\mathrm{q}$ value can be roughly evaluated using the weight average molecular weight of Lys $\left(14.3 \mathrm{kDa}^{39}\right)$ and that of $\mathrm{GelA}(3000$ $\mathrm{kDa}$ ), resulting in a ratio of $\sim 313: 1$. It should be noted that it is assumed here that the presence of Lys does not affect the molecular weight of GelA. This ratio clearly indicates the complexation of a large amount of Lys molecules, which can be considered as ligands, on one GelA nucleus, a mechanism exhibited frequently during interactions of weak polyelectrolytes. It should be noted that this dependence on the weight ratio q implies a dependence on the charge ratio, which will be explored in section 3.1.2.

\section{FIGURE 1}

240 Figure 1 reveals five domains of q (Fig. 1a,a',a") corresponding to (I) the absence of complexation, 241 (II) soluble complex formation (starting at qOnset), (III) phase separation of an insoluble complex ${ }^{35}$ (starting at $\mathrm{q}_{\phi}$ ), (IV) suppression of phase separation (starting at $\mathrm{q}^{*} \phi$ ), and (V) the absence of complexation (starting at $\mathrm{q}_{\mathrm{Set}}$ ). The $\mathrm{q}_{\phi}$ and $\mathrm{q}_{\phi}^{*}$ values delineate the phase boundaries and hence indicate complex stability. The weight ratio values corresponding to qonset, $\mathrm{q}_{\phi}, \mathrm{q}_{\mathrm{Max}}, \mathrm{q}^{*}{ }_{\phi}$ and $\mathrm{q}_{\mathrm{Set}}$ are $0.017,0.51,1.47,10.3$ and 93 respectively (Fig. 1a, a', a"). It is interesting to compare the complexation behavior of the Lys/GelA system with the Lys/sodium caseinate system studied 
recently at the same $\mathrm{pH}$ and $I$ values. ${ }^{37}$ It can be noted that, even though the total concentration of biopolymers in the initial binary solutions as well as the mixtures is higher for the Lys/GelA system, the maximal turbidity values of the Lys/sodium caseinate system are much higher as compared to that of the Lys/GelA system. This indicates that formation of water insoluble complexes is less intense in the case of the latter system. In addition, the $\mathrm{q}_{\phi}$ value for the Lys/GelA system is 1.6 times higher as compared to that obtained for the Lys/caseinate system ${ }^{37}$, i.e the complex system with gelatin undergoes associative phase separation in the presence of a more concentrated Lys solution, i.e. under more stringent conditions.

\subsubsection{Electrophoretic mobility and phase analysis.}

The $\varsigma$-potential of the complex mixtures is shown in Figure $1 \mathrm{~b}$ for a range of Lys/GelA and Lys/Gel weight ratios (q). At pH 7.0, GelA was found to have a net negative $\varsigma$-potential of -5.3 $\mathrm{mV}$, and a hydrodynamic radius $\mathrm{R}_{\mathrm{h}}=32 \mathrm{~nm}$. Lys has a hydrodynamic radius $\mathrm{R}_{\mathrm{h}}=1.9 \mathrm{~nm}$ and a net positive $\varsigma$-potential of $+3.0 \mathrm{mV}$ which is slightly less than the typical literature value of $+6 \mathrm{mV} .{ }^{40}$ This can be due to the presence of a small amount of aggregates, although the hydrodynamic radius of the lys sample $\left(\mathrm{R}_{\mathrm{h}}=1.9 \mathrm{~nm}\right)$ is the same as in literature. ${ }^{39}$ The negative charge of GelA is rapidly neutralized after adding Lys, and at even higher $q$ values the surface charge of the formed complexes becomes positive. Complete neutralization of the negative charge takes place at $\mathrm{q}=1.8$ 2.0 for the Lys/GelA system, i.e. at a q ratio that is slightly higher than that for maximal complexation as determined by the absorption measurements in Figure 1a. Possible reasons can be an irregular localization of Lys within the complex particles, inaccessibility of some cationic groups in Lys for interaction with GelA and effects of secondary forces in the interaction process. The results for the lys/Gel system will be discussed in Section 3.2.

Phase analysis was performed to obtain insight in the composition of the different phases in the complex mixtures. The isothermal phase diagram of the Lys/GelA system determined at $18^{\circ} \mathrm{C}$ is presented in Figure 2. The concentration range (below $11 \mathrm{wt} \%$ of both proteins) corresponding to a two-phasic state is relatively small and located mainly at comparable biopolymer concentrations with a small excess of Lys in the complex mixture. The complex phase is always gel like because it contains more than 4 wt\% GelA, whereas the supernatant is a dilute solution of both proteins. Phase analysis showed that the yield of Lys $\left(\mathrm{Y}_{\mathrm{Lys}}\right)$ in the biopolymer rich complex phase reaches its maximum (27\%) at $\mathrm{q}=1-1.4$. The inset presents the Lys/GelA weight ratio in the biopolymer rich complex phase $\left(\mathrm{q}^{*}\right)$ as a function of $\mathrm{q}$, as determined from phase analysis measurements. The weight ratio Lys/GelA in the complex phase depends only slightly on the weight ratio Lys/GelA in the system. This indicates that once the Lys concentration exceeds the "saturation" composition, completely neutralized polyelectrolyte 
complexes and completely free Lys coexist in the complex mixture. GelA chains partially covered by Lys thus appear to exhibit a higher reactivity than free GelA chains. These results show that complex formation in Lys/GelA systems occurs through an "all or none" type complexation. ${ }^{41}$

\section{FIGURE 2}

3.1.3 Size of the complexes.

The scattering intensity size distribution functions and number size distribution functions from DLS measurements for complex Lys/GelA particles are presented in Figure 3a,b. The total concentration of biopolymers was kept constant at $0.12 \mathrm{wt} \%$ whereas the Lys/GelA weight ratio q was varied in a range from 0.45 to 90 . Figure 3 a shows that the GelA sample is clearly polydisperse. The maximal scattering intensity is observed at an average particle radius of $270 \mathrm{~nm}$ (Fig. 3a). Smaller contributions from low molecular weight fractions with average sizes of 56.7 $\mathrm{nm}(27 \%)$ and $4.6 \mathrm{~nm}(8 \%)$ were also detected. The average radius of the Lys monomer was 1.9 $\mathrm{nm}$ (data not shown), which corresponds to literature results. ${ }^{42}$ The large difference in size between Lys and GelA allows to study changes in the GelA particle size in the presence of Lys. As can be seen in Fig. 3a, even in the presence of a relatively small amount of Lys in the GelA solution (at $\mathrm{q}=0.45$ ), the average radius increases to $498 \mathrm{~nm}$. For most q values studied, the complex particles are characterized by a narrow number size distribution. The number average radius of the complex particles as a function of $\mathrm{q}$ is shown in Figure 3b'. The maximum particle radius of $3500 \mathrm{~nm}$ is obtained for q=1.47-2.04 and the radius decreases sharply when q differs from this optimal value. When comparing this behavior with the results in Figs. 1 and 2 it can be seen that the maximal radius of the particles occurs at the $q$ value corresponding to the maximal absorption of the system and maximal yield of the complex. Figure $1 \mathrm{~b}$ further indicates that this coincides with the $q$ value at which a compensation of positive and negative charges occurs and the surface charge of the complexes thus becomes zero.

\section{FIGURE 3}

\subsubsection{Structure of the complex particles.}

310 Confocal Laser Scanning Microscopy (CLSM) was applied to monitor the distribution of Lys and GelA within Lys/GelA complexes at different q values, as illustrated in Figure 4a-d. The q values of $0.7,1.47,2.0$ and 5.0 were chosen to span the composition range from an excess of GelA, via maximal complexation $(\mathrm{q}=1.47)$ to an excess of Lys. It can be seen that at first approximation the intensity signal from GelA and Lys is weakly dependent on the Lys weight ratio in the complex 
system. In order to quantify the effect of q on the distribution of Lys within Lys/GelA complexes, the total intensity contribution of both components separately (green for GelA and orange for Lys) as well as its distribution over the particles was analyzed (results not shown). The total contribution of Lys or GelA in each particle remains more or less unaltered, independent of q. This suggests the presence of particles with a constant composition and total charge close to zero for all studied q values between 0.7 and 5. This is in agreement with the results of the phase analysis of the complex phase and supernatant in Figure 2. However, locally there are regions of the complex particles with an excess of fluorescence intensity of one of the biopolymers indicating that the total charge is distributed heterogeneously within the complex particles. The presence of yellow zones, resulting from a combination of green and orange indicates a homogeneous and fine distribution of Lys on the GelA in these zones.

\section{FIGURE 4}

\subsubsection{Protein structure within the complexes and binding constant.}

The protein structure within the complexes was analysed with fluorescence spectroscopy in the visible region. Fluorescence emission spectra were recorded in the range of 280-450 nm upon excitation at $280 \mathrm{~nm}\left(\lambda_{\mathrm{exc}}=280 \mathrm{~nm}\right)$. Figure 5a shows the fluorescence emission spectra of Lys and complex Lys/GelA systems at different $q$ values. The wavelength of maximum emission $\left(\lambda_{\max }\right)$ for Lys is about $337 \mathrm{~nm}$. In general, the fluorescence of tryptophan is stronger than that of

where $F_{o}$ and $F$ are the fluorescence intensities in the absence and presence of quencher, respectively, [Q] is the concentration of the quencher and $\mathrm{K}_{\mathrm{SV}}$ is the Stern-Volmer dynamic quenching constant. The latter constant is composed of the bimolecular quenching rate constant $\mathrm{K}_{\mathrm{q}}$ and the excited state life time $\tau_{0}$ of Lys in the absence of quencher. The value of $\mathrm{K}_{\mathrm{SV}}$ determined from the fluorescence measurements is $1.19 \cdot 10^{6} \mathrm{M}^{-1}$. If $\tau_{0}$ is taken as $10^{-8} \mathrm{~s},{ }^{47}$ a value for $\mathrm{K}_{\mathrm{q}}$ of 
$1.19 \cdot 10^{13} \mathrm{M}^{-1}$ is obtained. The maximum bimolecular quenching rate constant $\mathrm{K}_{\mathrm{q}}$ of various quenchers with biomacromolecules is known to be about $2.0 \cdot 10^{10} \mathrm{M}^{-1}$. ${ }^{4}$ The fact that our measurements reveal a value that is several orders of magnitude higher indicates that dynamic quenching is not the mechanism occurring in the Lys/GelA systems. Rather, static quenching arising from the formation of Lys/GelA complexes takes place.

Although dynamic quenching affects the excited state, it has no effect on the absorption spectrum. Hence, the UV absorption spectra of Lys were recorded with the addition of different GelA concentrations (data not shown). The absorbance of Lys increases with the presence of GelA, indicating that there is an interaction between Lys and GelA that involves the formation of a ground state complex of the type Lys/GelA. ${ }^{48}$ Hence, it can be concluded that static quenching is the dominant quenching mechanism, as already concluded from the analysis of the fluorescence quenching data. To further analyze the quenching data, the modified Stern - Volmer equation was applied: ${ }^{49}$

$$
\frac{F}{F_{o}-F}=\frac{1}{Q f K}+\frac{1}{f}
$$

where $\mathrm{f}$ is the fraction of the initial fluorescence that is accessible to the quencher and $\mathrm{K}$ is the Stern -Volmer quenching constant. For Lys, $\mathrm{f}=1$ suggesting that all the tryptophan residues are accessible to the quencher. ${ }^{50}$ The binding constant determined by this method is equal to $1.19 \cdot 10^{6}$ $\mathrm{M}^{-1}$. For binding of proteins to the double helix of DNA, values of the same order of magnitude have been reported. ${ }^{51}$ The fluorescence emission spectra of Lys/Gel systems in Fig. $5 \mathrm{~b}$ are discussed in Section 3.2.

\subsubsection{Rheological behavior of the complex systems}

Rheology is used to study the mechanical properties of the coacervates and to characterize the effect of the intermacromolecular interactions on the mechanical properties of the complex system. In order to do that the mechanical spectrum of complex Lys/GelA systems should be compared to that of a GelA solution with the same concentration of GelA, if possible close to that used for absorption and microscopy measurements. However the rheological response at such low concentrations was too weak to characterize. Therefore all rheological measurements were performed with a system containing $0.55 \mathrm{wt} \%$ gelatin. Nevertheless, similar to the system containing $0.12 \mathrm{wt} \%$ GelA (Fig. 1) the Lys/GelA system with $0.55 \mathrm{wt} \%$ gelatin is two-phasic in the q range studied (from 0.5 to 3.6). Note that at such a GelA concentration, the GelA solution contains large gel-like GelA particles with an average radius of $400 \mathrm{~nm}$. Such GelA solutions were stable against aggregation at $18^{\circ} \mathrm{C}$ during $8 \mathrm{~h}$. The dynamic moduli of Lys(variable)/GelA $(0.55$ $\mathrm{wt} \%$ ) systems were investigated as a function of q (Figure 6a). The viscoelastic behavior was compared with that of the buffer/GelA $(0.55 \mathrm{wt} \%)$ system without Lys. The binary gelatin solution 
is clearly an entangled polymer solution, for which viscous behavior dominates at low frequencies whereas elastic behavior dominates at high frequencies. In the presence of Lys, the formation of water insoluble complexes is observed, and this phase transition leads to a sharp increase of the moduli and decrease of the slope of G' and G' with frequency. This points to the formation of a network structure, which exhibits the rheological response of a gel. The fact that G' and G" nearly exhibit a frequency independent behavior suggests that relaxation is absent or at least postponed to very large timescales which are inaccessible with the present technique. The increase of the moduli and decrease of their frequency dependency result from the fact that the GelA concentration in the complex phase exceeds the gelation concentration of GelA. When q increases above 1, the modulus values drop again and also the frequency dependency of the moduli slightly increases, which points to an increase of the flexibility and relaxation possibilities of the formed network. This can be explained by the fact that at higher q ratios there is less free gelatin available for network formation as most gelatin is present in Lys/GelA complexes.

\section{FIGURE 6}

\subsection{Gelatin in unordered coil conformation.}

\subsubsection{Phase state of the Lys/Gel system at $\mathrm{pH} 7.0$ and $\mathrm{I}=0.01$}

It is well known that gelatin undergoes a completely reversible helix-coil transition after heating above $35^{\circ} \mathrm{C}$. Figure $7 \mathrm{a}$ presents the $\tau_{500}$ values of Lys/GelA systems with various concentrations of GelA $\left(\mathrm{C}_{\mathrm{GelA}}\right)$ and $\mathrm{q}=1.47$ as a function of temperature. Depending on the $\mathrm{C}_{\mathrm{GelA}}$ in the complex mixture, the temperature of the phase transition from the two-phasic state to the single phase state $\left(\mathrm{T}_{\text {Onset }}\right.$ ) changes from $35.6^{\circ} \mathrm{C}$ at $\mathrm{C}_{\mathrm{GelA}}=0.50 \mathrm{wt} \%$ to $34.9^{\circ} \mathrm{C}$ at $\mathrm{C}_{\mathrm{GelA}}=0.15 \mathrm{wt} \%$, and $28.7^{\circ} \mathrm{C}$ at $\mathrm{C}_{\mathrm{Gel} A}=0.10 \mathrm{wt} \%$. Accordingly, the phase transition point $\left(\mathrm{T}_{\phi}\right)$ determined as described in section 2.2.1 and shown in Fig. 7a changes from $30^{\circ} \mathrm{C}$ to $28.5^{\circ} \mathrm{C}$ and $27.5^{\circ} \mathrm{C}$. At temperatures equal to and above $35^{\circ} \mathrm{C}$ the complex system consists of a single phase at any concentration of GelA studied (up to $20 \mathrm{wt} \%$ ). Figure $7 \mathrm{~b}$ shows the phase diagram of Lys/GelA systems as a function of the protein concentrations and temperature. The phase diagram has an upper critical point. The formation of water insoluble complex particles is completely suppressed at temperatures above $35^{\circ} \mathrm{C}$, when the gelatin molecules are in the coil state. It is important to note that associative phase separation of the Lys/Gel system was not observed in a wide range of $\mathrm{pH}$ values (3-10), gelatin concentrations $\left(10^{-3} \mathrm{wt} \%-20 \mathrm{wt} \%\right)$, weight ratios of Lys in the system (0.1$100)$, ionic strength values $(0.01-0.5)$ and temperatures $\left(38^{\circ} \mathrm{C}-58^{\circ} \mathrm{C}\right)$. 
416 Figure $1 \mathrm{~b}$, providing the $\varsigma$ potential of Lys/Gel systems, shows that at $\mathrm{pH} 7.0$, the negative charge 417 of Gel is neutralized after adding Lys at $\mathrm{q} \sim 2.4$, which is slightly higher as compared to that obtained for the Lys/GelA system at $18^{\circ} \mathrm{C}$. Such difference can be due to two factors namely the slightly more negative $\varsigma$-potential value of GelA (5.8) as compared to Gel (5.3) and the absence of aggregation and precipitation in the Lys/Gel system at $40^{\circ} \mathrm{C}$. The lower $\varsigma$-potential value of GelA could result from the lower measurement temperature because the $\varsigma$ potential increases with increasing temperature.

\section{FIGURE 7}

3.2.2.Peculiarities of associative interactions and assemblies of Lys and Gelatin (Gel) macromolecules.

The remaining question is whether the Lys/Gel system at the given conditions contains small water soluble complex particles consisting of a macromolecular assembly as a result of the interaction of the biopolymers or whether formation of complex associates does not occur in the coil state of the gelatin molecules? In order to answer this question we performed atomic force microscopy (AFM) to observe possible macromolecular assemblies in the Lys(variable)/Gel(0.02wt\%) system. The AFM probe scans the surface at a constant vertical (van der Waals) force between the probe and the dried specimen, and provides topographical information which can be presented in 3D images. Figure 8 shows a typical surface topography for $\operatorname{Gel}(0.02 \mathrm{wt} \%)$ alone and in the presence of Lys at $\mathrm{q}=1.0$. It was established that the parameter $\mathrm{R}_{\mathrm{q}}$ characterizing the root-mean-square roughness, which is given by the standard deviation of the height measurement data, for the complex mixture is much larger (1.66) as compared to that of the pure Gel solution (0.369). Even visually at least three differences can be seen between both images. First, the complex mixture contains much more particles than the solution of Gel alone. Second, the size of the particles in the complex mixture is larger as compared to that for Gel alone. Finally, the internal structure of the particles for the two systems is different. Gel particles appear homogeneous whereas in the case of the complex system the particles appear to have a complex internal structure. Therefore, we can conclude that Gel in the coil state interacts weakly with Lys forming water soluble complex associates.

FIGURE 8

Smaller scan size $\left(0.5 \times 0.5 \mu^{2}\right)$ three-dimensional AFM images illustrating the surface topography of $\mathrm{Gel}(0.02 \mathrm{wt} \%)$ alone and Lys(variable)/Gel(0.02 wt\%) systems at different q values are presented in Figure 9a-d. A color-scale is used to enhance the height distribution contrast. It 
can be seen that the surface of the Gel sample is rather flat whereas the complex Lys/Gel systems are characterized by the presence of prominent particles. The amount of such particles is considerable especially at $q=1.47$. Similarly, DLS showed the presence of small particles with a size up to $300 \mathrm{~nm}$. This size appeared to be rather insensitive to the q value of the system (data not shown). In order to roughly evaluate the concentration of Gel corresponding to the appearance of intermacromolecular assemblies in the Lys/Gel system at q=1.47, AFM images were acquired for systems with the same $\mathrm{q}$ value and concentrations of Gel equal to $0.0008 \mathrm{wt} \%$ and $0.002 \mathrm{wt} \%$ (Figure 9e-f). The data obtained were compared with those obtained for the Lys/Gel $(0.02 \mathrm{wt} \%)$ system at $\mathrm{q}=1.47$ in Fig. 9d. The surface for the Lys/Gel(0.0008 wt\%) system at low Gel concentration is smooth with an insignificant amount of particles whose sizes are equal to or less than the size of the particles in a Gel solution, whereas the surface of the Lys/Gel(0.002 wt\%) complex system with larger Gel concentration contains particles with a larger size $(>120 \mathrm{~nm})$, which can be considered as complex associates. The obtained AFM data allow to conclude that the interaction between Lys and Gel also takes place but since the intermacromolecular interaction is weak only small water soluble complex associates are formed starting from a Gel concentration in the system of approximately $0.002 \mathrm{wt} \%$.

\section{FIGURE 9}

Fluorescence analysis was performed for the Lys/Gel system as shown in Fig. 5b and the binding constant was determined by using the modified Stern - Volmer method described above. The value obtained was $3.52 \cdot 10^{4} \mathrm{M}^{-1}$, which is a factor 100 lower as compared to that determined for the Lys/GelA system. This reduced binding constant is clearly reflected in the absence of associative phase separation.

\subsubsection{Thermal stability of lysozyme in the presence of gelatin}

DSMC was used to study the thermal stability of Lys in the presence of gelatin. The DSMC traces obtained from heating scans of a $0.125 \mathrm{wt} \%$ solution of free Lys and a complex Lys/GelA system at $\mathrm{q}=0.5$ and $1.0, \mathrm{pH} 7.0$ and ionic strength $I=0.01$ are presented in Figure 10. Both free Lys and Lys in the presence of gelatin exhibit almost reversible thermal unfolding. The DSMC thermogram of Lys could be fitted using one single transition with a melting temperature $\left(\mathrm{T}_{\mathrm{m}}\right)$ of approximately $75.2 \pm 0.3^{\circ} \mathrm{C}$ and overall unfolding enthalpy of $37.2 \pm 0.6 \mathrm{~J} / \mathrm{g}$. The obtained results are similar to those presented by Van de Weert and coworkers. ${ }^{52}$ The thermal behavior of Lys in the complex Lys/GelA system differs only 
slightly from that of pure Lys. The melting peak maximum shifts from $75.2 \pm 0.3^{\circ} \mathrm{C}$ for free Lys to $73.6 \pm 0.3^{\circ} \mathrm{C}$ for the complex Lys/GelA system, whereas the overall unfolding enthalpy decreases from $37.2 \pm 0.6 \mathrm{~J} / \mathrm{g}$ to $34.1 \pm 0.6 \mathrm{~J} / \mathrm{g}$. A further increase of the weight ratio of Lys in the mixture up to $\mathrm{q}=2$ does not lead to appreciable changes of the thermodynamic parameters of denaturation (data not presented). Such insignificant changes in the thermodynamic parameters of denaturation of Lys in the presence of gelatin favourably differ from the decrease of these parameters for complex systems comprising of Lys and anionic polyelectrolytes, such as heparin, ${ }^{52}$ dextran sulphate,${ }^{53}$ polyvinylsulfate, ${ }^{54}$ polyacrylic and methacrylic acid. ${ }^{54}$

\section{FIGURE 10}

\subsubsection{Peculiarity of the phase behavior: Applicability of existing theories}

The experimental data show the principal role of the helix-coil transition in gelatin on the phase state in mixed solutions of Lys and gelatin. The difference in phase state is clearly linked to the large difference in binding constant between systems containing either Gel or GelA. Actually, the Lys/Gel system remains a single phase over a wide range of $\mathrm{pH}$, ionic strength, temperature and $\mathrm{q}$ values despite the fact that the average radius of the Gel particles is only 2.2 times less than that of GelA particles (data not shown). The question thus arises what is the driving force for this phenomenon? There are several theoretical approaches of complex coacervation in macromolecular solutions composed of two oppositely charged macro-ions into two immiscible liquid phases: the Voorn-Overbeek theory ${ }^{55,56}$ and its extension by Nakajima and Sato ${ }^{57}$, the VeisAranyi "dilute phase aggregate model" ${ }^{58}$ and its extension by Tainaka ${ }^{59}$ and the PRISM-type theory ${ }^{60}$ qualitatively (and sometimes quantitatively) agree with experimental data. These theories differ in several aspects such as the roles of electrostatic and entropic forces, the importance of Huggins interactions, and the nature of the charge interaction. ${ }^{61}$ Describing the (correlated) charge distribution in the systems is however very complex and this limits theoretical developments. ${ }^{62}$ The Voorn-Overbeek theory ${ }^{55,56}$ provides the first thermodynamic model of polyelectrolyte coacervation that includes both entropic and electrostatic interactions, which were taken into account by a mean-field approach. Entropic forces are described with the Flory-Huggins theory of polymer solutions and favor mixing. The electrostatic interactions are described with the Debye-Hückel theory and favor phase separation resulting in the presence of a dense phase containing polyelectrolyte complexes. The final phase behavior is based on the competition between both types of interactions. Burgess ${ }^{61}$ has shown that the Voorn-Overbeek theory is inadequate to describe gelatin/arabic gum coacervation under the variety of conditions studied. On the other hand, the Veís-Aranyi model ${ }^{58}$ as adapted by Tainaka ${ }^{59}$ explained most of this data. ${ }^{61}$ 
This theory suggested an alternate two-step mechanism of coacervation in which the electrostatic interactions between the polyions first lead to the formation of neutral aggregates, after which hydrophobic interactions cause coalescence of the aggregates into a coacervate phase. The capabilities of these two theories and their subsequent modifications to describe the behavior of a range of systems containing for instance gelatin, albumin and Arabic gum were reviewed by Burgess. ${ }^{61}$ Most of these theoretical approaches analyzed protein-PE and protein-polysaccharide systems. Theoretical approaches for interactions in protein-protein systems analyze mainly intermacromolecular contacts, possible structures and configurations of the complexes ${ }^{63}$ but not the critical conditions for associative phase separation. Since an appropriate theory to analyze phase transitions in protein-protein systems is lacking for the moment, an attempt is made to explain the single phase state on the basis of one of the above mentioned models for complex coacervation in protein-PE systems. It has been shown for many protein-PE systems that temperature has a minor effect on the phase diagram. Entropy gain is the main driver of complex coacervation, due to the concomitant release of bound counterions in solution by the interacting charged biopolymers, which increases the solution entropy. Such conclusion was based on isothermal calorimetry experiments showing the temperature independence of the transition. ${ }^{62}$ In the case of the Lys/Gel system such explanation is not appropriate because we observe a strong effect of temperature on the phase separation. At first sight the Veís-Aranyi model should be more suitable to describe the phase behavior of Lys/gelatin systems because it was successful in describing complex coacervation in another gelatin containing system. However the Veís-Aranyi theory predicts suppression of complex coacervation at low and high ionic strength whereas the Voorn-Overbeek theory predicts the presence of complex coacervation at low ionic strength and its suppression at high ionic strength. Since complex coacervation of Lys/GelA systems only takes place at low ionic strength we expect that Lys/Gel phase separation follows the Voorn-Overbeek model. A more in depth study of the quantitative applicability of the model for the Lys/Gel system is beyond the scope of the present work.

\section{4. CONCLUSION}

The interaction and associative phase separation of hen egg white Lys and bovine skin gelatin was investigated with particular emphasis on the effect of the helix-coil conformational changes of gelatin. Atomic force and confocal laser scanning microscopy, phase analysis, dynamic and electrophoretic light scattering, turbidimetry, absorption and fluorescence spectroscopy were used to study Lys/gelatin systems at different temperatures $\left(18^{\circ} \mathrm{C}\right.$ and $\left.40^{\circ} \mathrm{C}\right)$ for various Lys/Gelatin weight ratios (0.01-100) at $\mathrm{pH} 7.0$ and low ionic strength $(I=0.01)$. It was established that associative phase separation only occurs for the system with Gel in the helix state. The Lys/GelA 
553 depend on the charge ratio of the complex solutions, which is governed by the Lys concentration.

554 Complexation takes place at low ionic strength (0.01) and decreases sharply after increasing the

555 ionic strength. When the weight ratio $(q) \sim 0.017-0.50$, i.e. when the average zeta potential of the 556 complex particles $(\zeta)$ is negative, complexation leads mainly to the formation of water-soluble 557 complexes. At higher q values ( 0.55-9.0), large (1000-3000 nm in radius) water insoluble 558 complex particles are formed with an approximately constant composition $(\sim 1.47 \mathrm{wt} / \mathrm{wt}$ or $313: 1$

559 mole/mole Lys/gelatin ratio) by an all or none type mechanism. When the q values are $\geq 10.5$, 560 formation of water soluble complexes takes place. Confocal laser scanning microscopy clearly 561 showed that the allocation of the Lys and Gel molecules within the complex particles has a 562 heterogeneous character. Binding of Lys takes place without significant changes in its tertiary 563 structure. The thermal stability of Lys within the complex mixture and its enthalpy of denaturation 564 decrease insignificantly as compared to the behaviour of complexes of Lys with sulphated 565 polysaccharides. ${ }^{47}$ Gel in the coil state only interacts weakly with Lys forming water soluble 566 complex associates. Figure 11 presents a scheme illustrating the formation of water insoluble and 567 water soluble complexes for the two conformational states of gelatin. The stronger binding and 568 phase separation in the case of the helix state of Gel may be described on the basis of the Voorn569 Overbeek model. The present study has provided important insights in the associative phase 570 separation in protein- protein and protein-weak PE systems.

\section{FIGURE 11}

\section{ACKNOWLEDGMENT}

Y.A. Antonov is grateful to KU Leuven for financial support from the Soft Matter Rheology and Technology group. We are thankful to Prof. Dr. Mark Van der Auweraer (Molecular Imaging and Photonics, KU Leuven) for providing access to the fluorescence spectroscopy instrumentation.

\section{References}

580 (1) Lodish, H.; Berk,A.; Zipursky, S. L.; Matsudaira, P., Baltimore, D. and Darnell, J. 10: 0-7167 3136-3.

583 (2) Siebert, H.C. Carbohydrate-Protein Interaction Status and Perspectives. In Glycosciences;

584 Gabius, H. J., Gabius, S. Eds.; Chapman and Hall: London, 1997; Ch. 16, pp.291-310.

585 (3) Toida, T.; Chaidedgumjorn, A.; Linhardt, R. J. Structure and bioactivity of sulfated polysaccharides. Trends Glycosci. Glycotechnol. 2003, 15, 29-46. 
(4) Howell, N. J.; Sabila, Y.; Grootveld, M.; \& Williams, S. High-resolution NMR and magnetic resonance imaging (MRI) studies on fresh and frozen cod J. Sci. Food Agric.,1996,72, 49-56.

(5) Bouhallab, S.; Croguenneg, T. Spontaneous assembly and induced aggregation of food proteins. Adv.Polym.Sci.2014, 256, 67-102.

(6) Adal,E.; Sadeghpour,A.; Connell,S.; Rappolt,M.; Ibanoglu,E.; and Sarkar,A. Heteroprotein Complex Formation of Bovine Lactoferrin and Pea Protein Isolate: A Multiscale Structural Analysis. Biomacromolecules, 2017, 18 (2), 625-635.

(7) Anema,S.G.; and de Kruif,C.G. Interaction of lactoferrin and lysozyme with casein micelles Biomacromolecules, 2011, 12 (11), 3970-3976.
(8) Yan,Y.; Kizilay,E. Seeman, D.; Flanagan,S. Dubin,P.L.; Bovetto, L.; Donato, L.; and Schmitt.C. Heteroprotein Complex Coacervation: Bovine $\beta$-Lactoglobulin and Lactoferrin Langmuir, 2013, 29 (50), 15614-15623.

(9) Tribet, C. Complexation between amphiphilic polyelectrolytes and proteins: from necklaces to Gels. In Physical Chemistry of Polyelectrolytes; Radeva, T. Ed.; Marcel Dekker: New York, 2001; 687-741.

\section{(10) Xia, J.; Dubin, P. Protein-polyelectrolyte complexs. In Macromolecular Complexes in} Chemistry and Biology; Dubin, P.L.; Bock, J.; Davies, R.M.; Schulz, D.N. Eds.; SpringerVerlag: Berlin, 1994, pp. 247-271.

(11) Ducel, V.; Richard, J.; Saulnier, P.; Popineau Y.; Boury, F. Evidence and characterization of complex coacervates containing plant proteins: application to the microencapsulation of oil droplets. Colloids Surf. A 2004, 232, 239-247.

(12) Singh, O. N. and Burgess, D. J. Development of a novel method of microencapsulation for a model protein, $\beta$-glucuronidase. Pharm. Sci. 1996, 2, 223-228.

(13) Jiang, Y.; Huang, Q. Microencapsulation and controlled-release of food enzyme using protein-polysaccharide coacervates. Abstracts of Papers, 228th ACS National Meeting (Philadelphia, PA), 2004, American Chemical Society: Washington DC.

(14) Encapsulation and controlled release technologies in food systems. Second edition. Eds Dr Jamileh M. Lakkis. John Wiley \& Sons, 2016. Molecular Mechanisms to Large-Scale Processes; Ladisch, M., Willson, R. C., Painton, C. C., Builder, S. E., Eds.; American Chemical Society: Washington, DC, 1990; Chapter 5. (16) Dickinson, E. Colloids in Food: Ingredients, Structure, and Stability. Food science and Technology. 2015, 6, 211-233. 
(17) Kabanov, V. A. Basic properties of soluble interpolyelectrolyte complexes applied to bioengineering and cell transformations. In Macromolecular complexes in chemistry and biology; Dubin, P. L. Ed.; Springer-Verlag: Berlin, pp. 151-174, 1994.

(18) Seyrek, E.; Tribet, C.; Dubin, P. L.; Gamble, E. A. Ionic strength dependence of protein polyelectrolyte interactions. Biomacromolecules 2003, 4, 273-282.

(19) Stewart, R. J.; Wang, C. S.; Shao, H. Complex coacervates as a foundation for synthetic underwater adhesives. Adv. Colloid Interface Sci. 2011, 167, 85-93.

(20) Winkler, R.G.; Roland,G.; \& Cherstvy, A.G. Strong and weak polyelectrolyte adsorption onto oppositely charged curved surfaces In M. Muller, (Ed), Polyelectrolyte complexes in the dispersed and solid state.I. Principles and theory (pp.1-56).New York: Springer.2014.

(21) Desfougères, Y.; Croguennec, T.; Lechevalier, V.; Bouhallab, S.; \& Nau, F. (2010). Charge and Size Drive Spontaneous Self-Assembly of Oppositely Charged Globular Proteins into Microspheres. J Phys. Chem. B, 2010,II4, 4138-4144.

(22) Van der Linden, E., \& Venema, P. (2007). Self-assembly and aggregation of proteins. Curr. Opin. Colloid Interface Sci.,2007,12, 158-165.

(23) Coers, J.; Permyakov, S. E.; Permyakov, E. A.; Uversky, V. N.; Fink, A. L. Conformational prerequisites for $\alpha$-lactalbumin fibrillation. Biochemistry, 2002, 41, 12546-12551.

(24) Krebs, M. R. H.; Wilkins, D. K.; Chung, E.W;, Pitkeathly, M. C.; Chamberlain, A. K.; Zurdo, J.; Robinson, C.V.; \& Dobson, C. M. Formation and seeding of amyloid fibrils from wild type hen lysozyme and a peptide fragment from the $\beta$-domain. J.Mol. Biol., 2000, 300, 541549.

(25) Sagis, LMC.; Veerman,C.; van der Linden,E. Mesoscopic properties of semiflexible amyloid fibrils Langmuir 2004, 20 (3), 924-927.

(26) Krebs, M.R.H.; Delvin, G.L.; \& Donald, A.M. (2007). Protein particulates: another generic form of protein aggregation? Biophys.J.,2007, 92, 1336-1342.

(27) Antonov, Y. A., Zhuravleva, I. L. Macromolecular complexes of BSA with gelatin. International Journal of Biological Macromolecules 2012, 51, 319- 328.

(28) Privalov, P.L.; Khechinashvili, N. N. A thermodynamic approach to the problem of Stabilization of globular protein structure: a calorimetric study. J Mol Biol. 1974, 86 (3), 665-84. (29) Djabourov, M.; Leblond J.; Papon, P. Gelation of aqueous gelatin solutions. I. Structural investigation. Journal de Physique France 1988, 49, 319-332.

(30) Migneault, I.; Dartiguenave, C.; Bertrand, M. J.; Waldron, K. C. Gluteraldehyde: behavior in aqueous solution, reaction with proteins, and application to enzyme crosslinking. BioTechniques 2004, 37, 790-802. 
(31) Boedtker, H.; Doty, P. A. Study of Gelatin Molecules, Aggregates and Gels. J.Phys. Chem. 1954, 58, 968-983.

(32) Williams, J.W.; Saunders,W.M.; Cicerelli, J.S. Size Distribution Analysis in Plasma Extender Systems. I. Gelatin. J. Phys. Chem. 1954, 58, 774-782.

(33) Masuelli, Martin Alberto. Mark-Houwink Parameters for Aqueous-Soluble Polymers and Biopolymers at Various Temperatures. J. of Polymer and Biopolymer Physics Chemistry, 2014, 2, (2), 37-43.

(34) Aune, K.C.; Tanford C. Thermodynamics of the denaturation of lysozyme by guanidine hydrochloride. I. Dependence on pH at 25 degrees. Biochemistry. 1969, 8, (11), 4579-4585. (35) Carlsson, F.; Lines, P.; \& Malmsten, M. Monte Carlo simulations of polyelectrolyte-protein complexation. J. Phys. Chem. B 2001, 105, 9040-9049.

(36) Antonov, Y.A.; Moldenaers,P.; Cardinaels, R. Complexation of lysozyme with sodium caseinate and micellar casein in aqueous buffered solutions. Food Hydrocolloids 2017, 62, 102118.

(37) Wiesendanger R. Scanning Probe Microscopy and Spectroscopy: Methods and Applications, Cambridge Univ. Press, Cambridge, UK, 1994.

(38) Privalov, P. L. Microcalorimetry of proteins and their complexes. In Protein Structure,Stability, and Interactions Shriver, J. W. Ed.; The Humana Press Inc.: Totowa, New Jersey, 2009, 7p.

(39) Thomas, B. R., Vekilov P.G.; Rosenberger F. Heterogeneity determination and purification of commercial hen egg-white lysozyme. Acta Crystallogrt. D Biol. Crystallogr. 52(Pt 4):776784, 1996.

(40) Kuehner, D. E.; Engmann, J.; Fergg, F.; Wernick, M.; Blanch, H. W.; Prausnitz, J. M. Lysozyme net charge and ion binding in concentrated aqueous electrolyte solutions. J. Phys. Chem. B 1999, 103, 1368-1374.

(41) Michaels, A. S.; Falkenstein, G. L.; \& Schneider, N. S. Dielectric properties of polyanion-polycation complexes. J. Phys. Chem. 1965, 69, 1456-1465.

(42) Parmar, A. S.; Muschol, M. Hydration and hydrodynamic interactions of lysozyme: effects of chaotropic vs. kosmotropic ions. Biophys. J. 2009, 97, 590-598.

(43) Lakowicz, J. R. Principles of fluorescence specytroscopy., Plenum: (New York and London: p. 496, 1986.

(44) Nishimoto, E.; Yamashita, S.; Szabo, A. G.; Imoto, T. Internal motion of lysozyme studied by time resolved fluorescence depolarization of tryptophan residues. Biochemistry 1998, 37, 5599-5607. 
(45) Stern, O.; Volmer, M. Über die Abklingzeit der Fluoreszenz. Physik. Zeitschr. 1919,

690

691

692

693

694

695

696

697

698

699

700

701

702

703

704

705

706

707

708

709

710

711

712

713

714

715

716

717

718

719

720

721

722 20,183-188.

(46) Ware, W. R. Oxygen quenching of fluorescence in solution: an experimental study of the diffusion process. J. Phys. Chem. 1962, 66, 455-458.

(47) Joseph, R. L.; Gregorio, W. Quenching of fluorescence by oxygen. Probe for structural fluctuations in macromolecules. Biochemistry 1973, 12, 4161-4170.

(48) Wang, Y. Q.; Zhang, H. M.; Zhou, Q. H. Studies on the interaction of caffeine with bovine hemoglobin. Eur. J. Med. Chem. 2009, 44, 2100-2105.

(49) Timaseff, S. N.Thermodynamics of protein interactions. In Proteins of Biological Fluids; Peeters, H. Ed.; Pergamon Press: Oxford 1972, pp. 511-519.

(50) Wang, W.; Min, W.; Chen, J.; Wu, X.; Hu, Z. Binding study of diprophylline with lysozyme by spectroscopic methods. J. Luminescence 2011, 131, 820-824.

(51) Szewczyk, J. W.; Baird, E. E., \& Dervan, P.B. Cooperative triple-helix formation via a minor groove dimerization domain. J. Am. Chem. Soc. 1996, 118, 6778-6779.

(52) Van de Weert, M.; Andersen, M. B.; Frokjaer, S. Complex coacervation of lysozyme and heparin: complex characterization and protein stability. Pharm. Res. 2004, 21, 2354-2359.

(53) Antonov, Y. A.; Zhuravleva, I. L.; Cardinaels, R.; Moldenaers, P. Structural studies on the interaction of lysozyme with dextran sulfate. Food Hydrocolloids 2015, 44, 71-80.

(54) Ivinova, O. N.; Izumrudov, V. A.; Muronetz, V. I.; Galaev, I. Yu.; Mattiasson, B. Influence of complexing polyanions on the thermostability of basic proteins. Macromol. Biosci. 2003, 3, 210-215.

(55) Overbeek, J. Th. G.; Voorn, M. J. Phase separation in polyelectrolyte solutions. Theory of complex coacervation. J. Cell. Comp. Physiol. 1957, 49 (Supp. I), 7.

(56) Voorn, M. J. Phase separation in polymer solutions. Fortschr. Hochpolym. Forsch. 1959,1, 192-233.

(57) Nakajima, A.; Sato, H., Phase relationships of an equivalent mixture of sulfated polyvinyl alcohol and aminoacetalyzed polyvinyl alcohol in microsalt aqueous solution. Biopolymers 1972, $10,1345-1355$.

(58) Veis, A.; Aranyi, C. Phase separation in polyelectrolyte systems. I. Complex coacervates of gelatin. J. Phys. Chem. 1960, 64, 1203-1210.

(59) Tainaka, K. Effect of counterions on complex coacervation. Biopolymers 1980, 19, 12891298.

(60) Perry, S., L.; Sing, C. E. PRISM-Based Theory of Complex Coacervation: Excluded Volume versus Chain Correlation. Macromolecules 2015, 48, 5040-5053. 
(61) Burgess, D.J. Practical Analysis of Complex Coacervate Systems. Journal of Colloid and 724 Interface Science 1990, 140(1), 227-238.

725 (62) de Kruif, C. G.; Weinbrecka, F.; de Vries, R. Complex coacervation of proteins and anionic polysaccharides. Current Opinion in Colloid \& Interface Science 2004, 9, 340 -349.

(63) Schreiber, G.; Shaul, Y.; Gottshalk K.E. Electrostatic design of protein-protein association rates. Methods Mol. Biol. 2006, 340, 235-249.

729

\section{Figure captions}

731

Figure 1. (a, a', a") Turbidity values at $500 \mathrm{~nm}\left(\tau_{500}\right)$ as a function of the weight ratio $\mathrm{q}\left(\frac{\mathrm{Lys}}{\mathrm{Gel}}\right)$ for Lys/GelA mixtures at $I=0.01, \mathrm{pH} 7.0$ and $18^{\circ} \mathrm{C}$. The total concentrations of Lys and GelA in the ternary mixtures $\left(\mathrm{C}^{\mathrm{M}}{ }_{\mathrm{Tot}}\right)$ and the concentrations of Lys and GelA in the binary solutions $\left(\mathrm{C}^{\mathrm{o}}{ }_{\text {Lys }}\right.$, $\left.\mathrm{C}^{\mathrm{o}} \mathrm{GelA}\right)$ were kept constant at $0.12 \mathrm{wt} \%$. In the insets (a', $\left.\mathrm{a}^{\prime \prime}\right)$ qOnset indicates the transition between no complex formation and formation of soluble complexes, $\mathrm{q}_{\phi}$ and $\mathrm{q}^{*}{ }_{\phi}$ indicate the beginning and ending of phase separation, and $\mathrm{q}_{\text {Set }}$ indicates the transition between formation of soluble complexes and no complex formation. (b) Zeta potential (s) as a function of weight ratio q for Lys/Gel and Lys/GelA mixtures at $I=0.01$ and $\mathrm{pH} 7.0$.

Figure 2. Isothermal phase diagram of the complex Lys/GelA system at $I=0.01, \mathrm{pH} 7.0$ and $18^{\circ} \mathrm{C}$. The inset presents the Lys/GelA weight ratio in the concentrated complex phase $\left(\mathrm{q}^{*}\right)$ as a function of the Lys/GelA weight ratio $q$ in the system. The thin red lines are the lines connecting the compositions of coexisting phases. The bold purple line is the binodal line, showing the border between the two phase and single phase states of the system.

Figure 3. (a) The intensity size distribution and (b) number size distribution for lys/GelA mixtures. The insert shows the average size of the complex Lys/GelA particles as a function of q. $\mathrm{C}^{\mathrm{M}}{ }_{\mathrm{tot}}=\mathrm{C}^{\mathrm{o}}{ }_{\mathrm{Lys}}=\mathrm{C}^{\mathrm{o}}{ }_{\mathrm{GelA}}=0.12 \mathrm{wt} \%, I=0.01, \mathrm{pH} 7.0$ and $18^{\circ} \mathrm{C}$.

Figure 4. Confocal microscopy images of Lys/GelA mixtures at different q values. (a) $q=0.8$, (b) $\mathrm{q}=1.5$, (c) $\mathrm{q}=2.0$ and (d) $\mathrm{q}=4.0$ for $\mathrm{C}^{\mathrm{M}}{ }_{\text {tot }}=\mathrm{C}^{\mathrm{o}}{ }_{\mathrm{Lys}}=\mathrm{C}^{\mathrm{o}}{ }_{\mathrm{GelA}}=0.2 \mathrm{wt} \%, I=0.01, \mathrm{pH} 7.0$ and $18^{\circ} \mathrm{C}$. GelA is labeled green and Lys is labeled orange.

Figure 5. Fluorescence spectra for a Lys solution and complex Lys/GelA (a) and Lys/Gel (b) mixtures at various q values. $\mathrm{C}^{\mathrm{M}}{ }_{\mathrm{Lys}}=0.005 \mathrm{wt} \%, I=0.01, \mathrm{pH} 7.0$, (a) $18^{\circ} \mathrm{C}$ and (b) $40^{\circ} \mathrm{C}$.

Figure 6. Dynamic moduli as a function of frequency for GelA solutions and Lys/GelA mixtures at various q values, after shearing at $500 \mathrm{~s}^{-1}$ for $900 \mathrm{~s}$ and subsequent rest for $30 \mathrm{~s} . \mathrm{C}^{\mathrm{M}}{ }_{\mathrm{Gel}} \mathrm{A}=0.55$ wt $\%, I=0.01, \mathrm{pH} 7.0$ and $18^{\circ} \mathrm{C}$.

Figure 7. (a) Turbidity values $\tau_{500}$ of the complex Lys/GelA system at $q=1.47$ as a function of temperature. Concentration of GelA: $\Delta-0.1 \mathrm{wt} \%$, o - $0.15 \mathrm{wt} \%, \bullet-0.5 \mathrm{wt} \%$. (b) 3D phase 
757 separation diagram of Lys/GelA system as a function of Lys concentration, GelA concentration

758 and temperature. The system forms complex coacervates inside the 3D body indicated by the

759 solid red lines. $I=0.01$ and $\mathrm{pH} 7.0$.

760 Figure 8. Topography of surfaces of (a) Gel solution and (b) Lys/Gel mixture. Both systems

761 were subjected to drying at $40^{\circ} \mathrm{C} . \mathrm{C}^{0}{ }_{\mathrm{Gel}}=\mathrm{C}^{\mathrm{M}}{ }_{\mathrm{Gel}}=\mathrm{C}^{\mathrm{M}}{ }_{\mathrm{Lys}}=0.02 \mathrm{wt} \%, I=0.01$ and $\mathrm{pH}$ 7.0.

762 Figure 9. Three-dimensional color $0.5 \times 0.5 \mu \mathrm{m}^{2}$ AFM height images for surfaces of Gel and

763 Lys/Gel mixtures at different q values. Systems were subjected to drying at $40{ }^{\circ} \mathrm{C}$.

$764 \mathrm{C}_{\mathrm{Gel}}^{0}=\mathrm{C}^{\mathrm{M}}{ }_{\mathrm{Gel}}=0.02 \mathrm{wt} \%, I=0.01$ and $\mathrm{pH}$ 7.0. a) Gel, (B-D) $\mathrm{C}^{0}{ }_{\mathrm{Gel}}=\mathrm{C}^{\mathrm{M}}$ Gel is $0.02 \mathrm{wt} \%, \mathrm{q}=0.5(\mathrm{~B})$,

$765 \mathrm{q}=1.0(\mathrm{C}), \mathrm{q}=1.47$ (D). (E,F) $\mathrm{q}=1.47$ with (E) $\mathrm{C}^{0}{ }_{\mathrm{Gel}}=0.0008 \mathrm{wt} \%,(\mathrm{~F}) \mathrm{C}_{\mathrm{Gel}}^{0}=0.002 \mathrm{wt} \%$.

766 Figure 10. DSMC traces for Lys and complex Lys/GelA mixtures at $q=0.5$ and $q=1.0$.

$767 \quad \mathrm{C}^{\mathrm{M}}{ }_{\mathrm{Lys}}=0.125 \mathrm{wt} \%, \mathrm{I}=0.01$ and $\mathrm{pH}$ 7.0.

768 Figure 11. Schematic illustrating the binding of Lys with gelatin in (a) ordered state and (b) coil 769 state. 

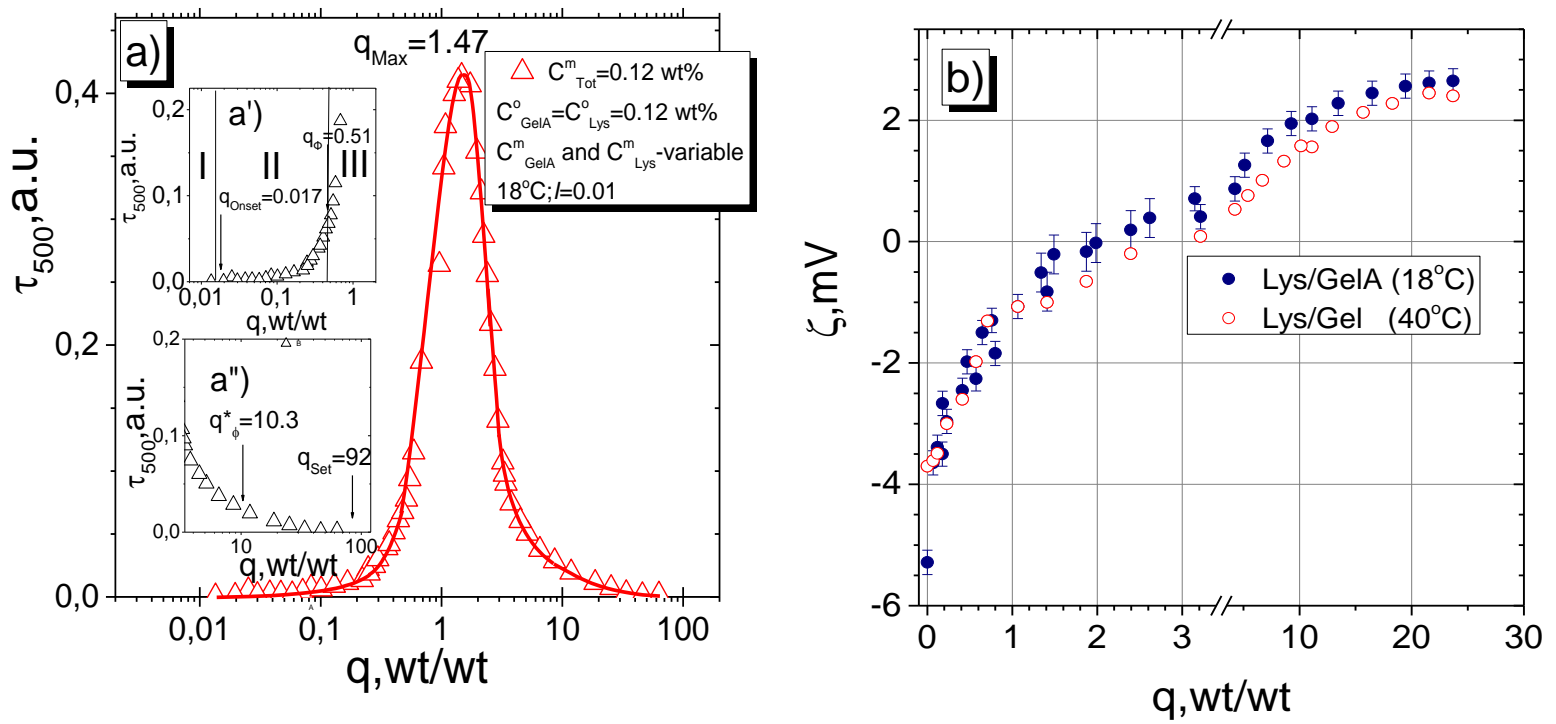

Figure 1 


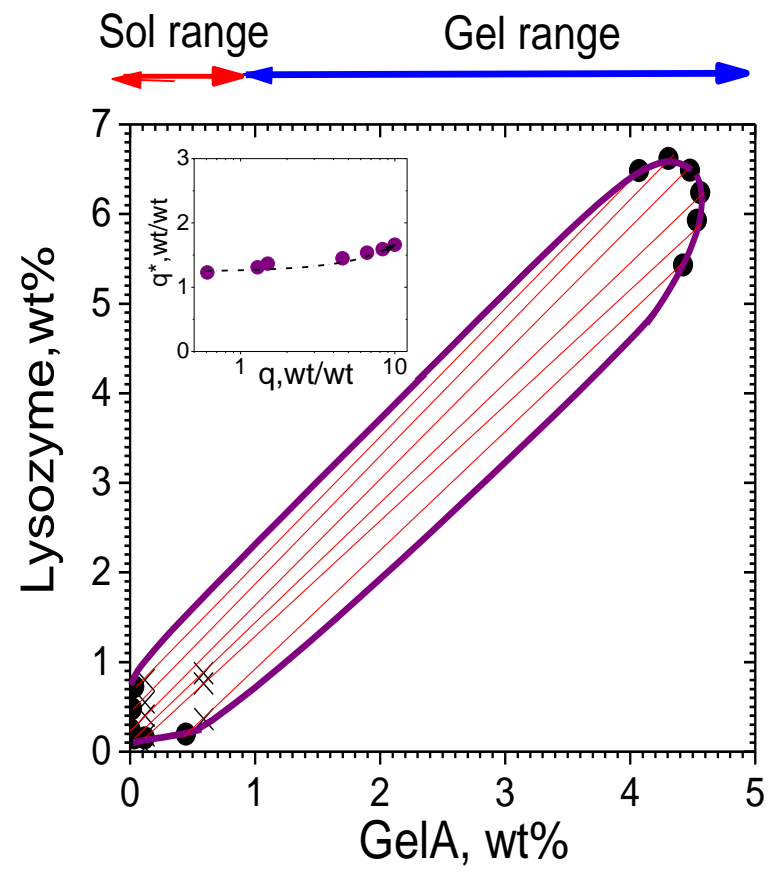

Figure 2 


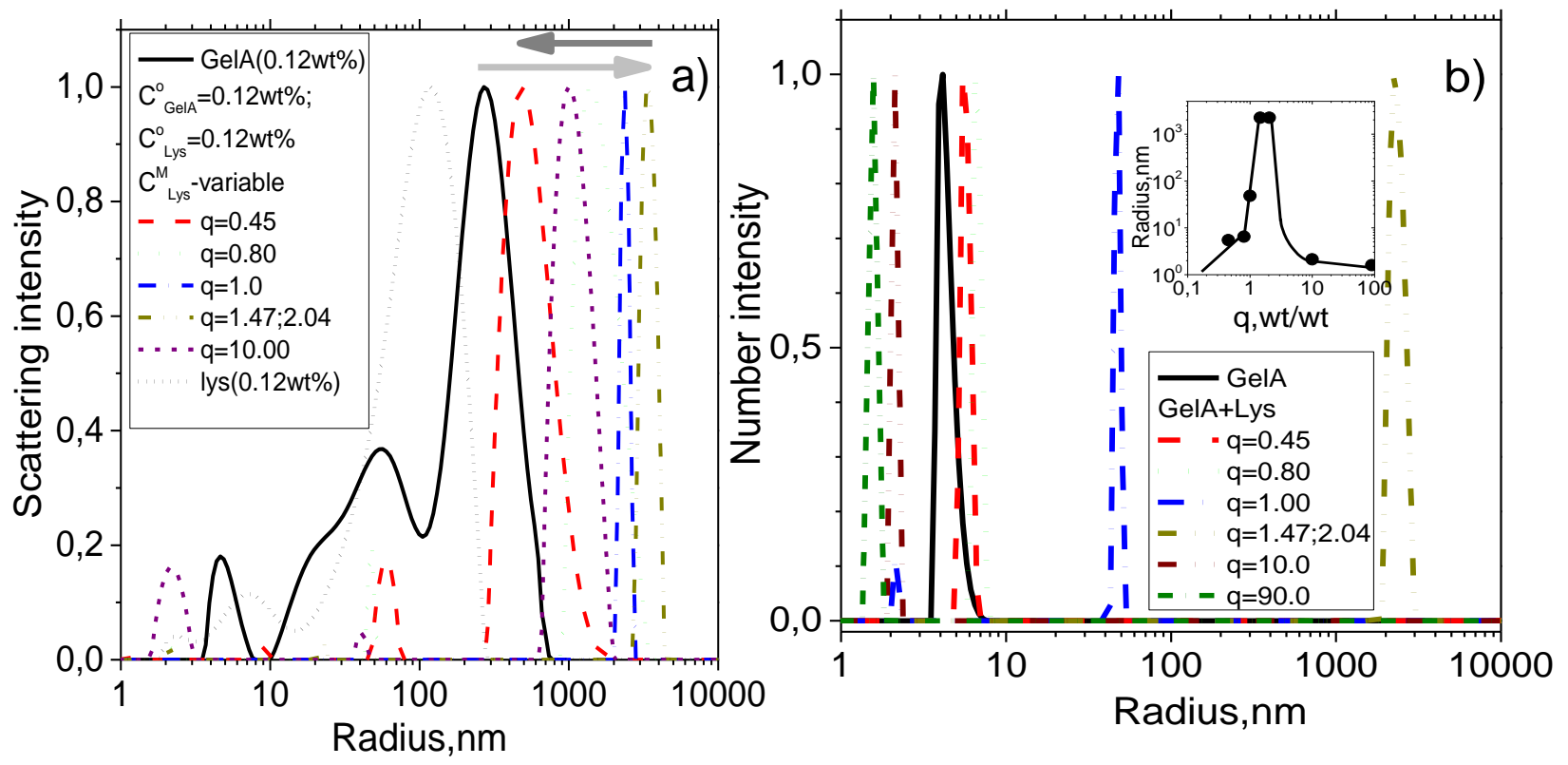

Figure 3. 


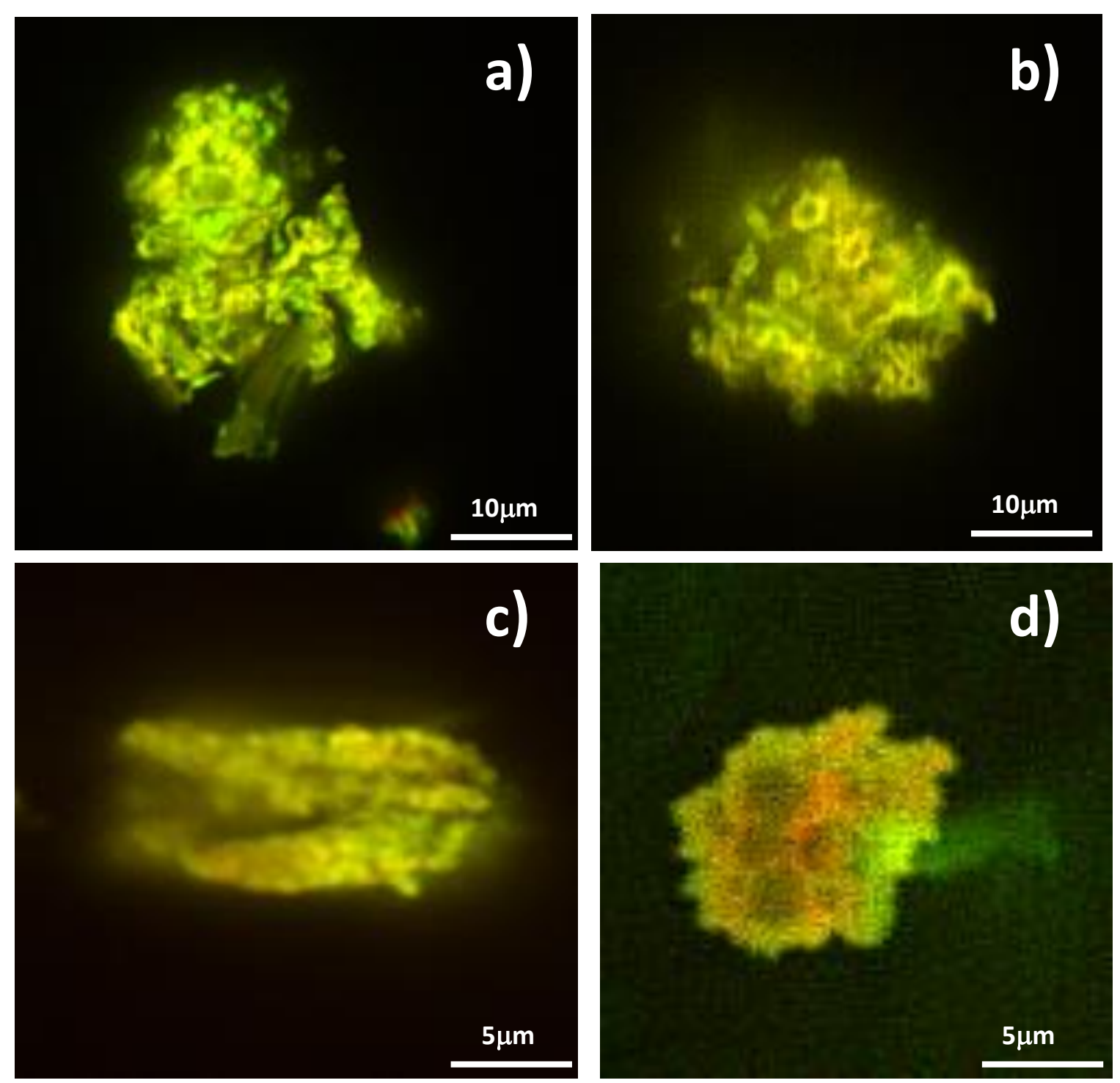

Figure 4. 

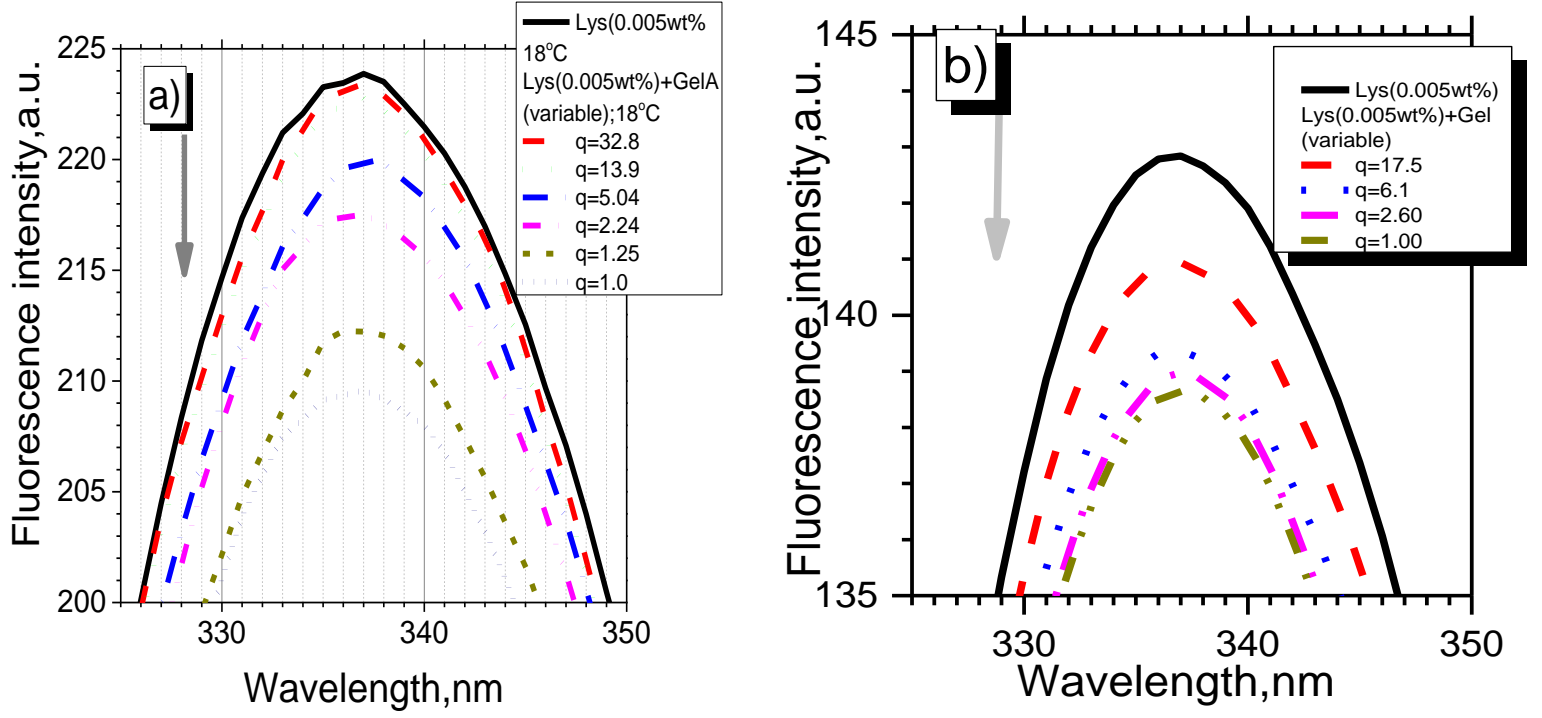

Figure 5 


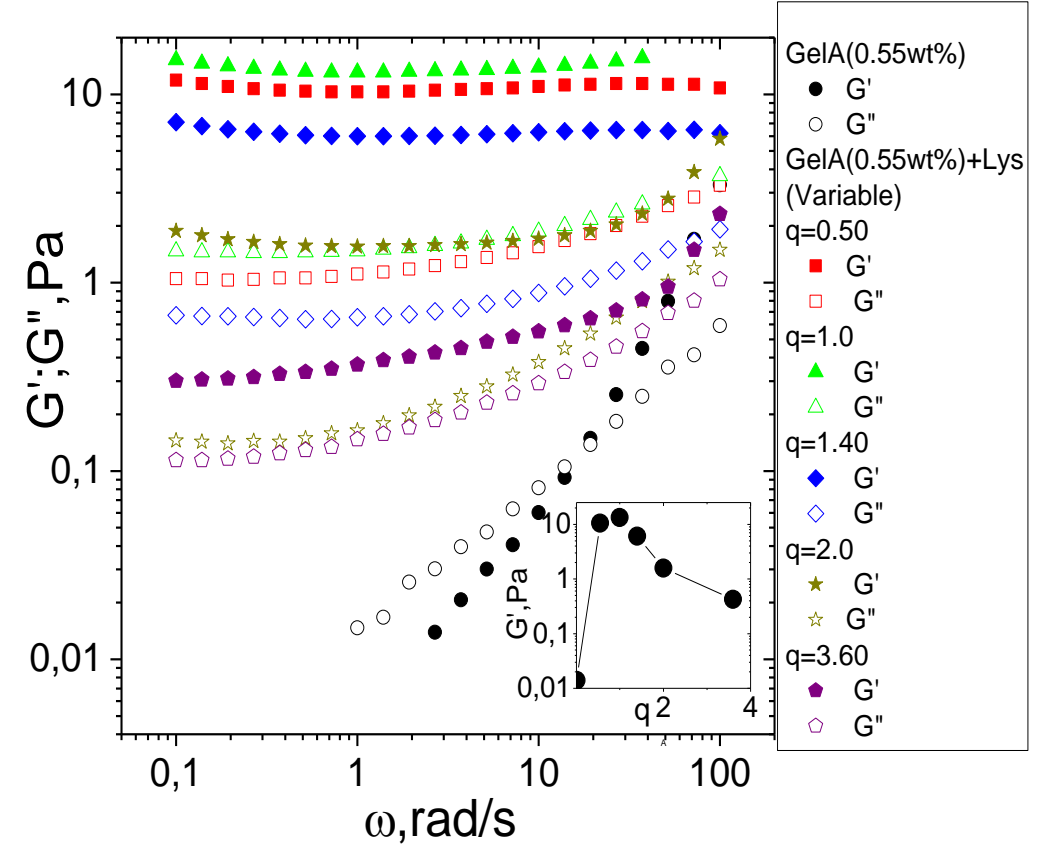

Figure 6. 


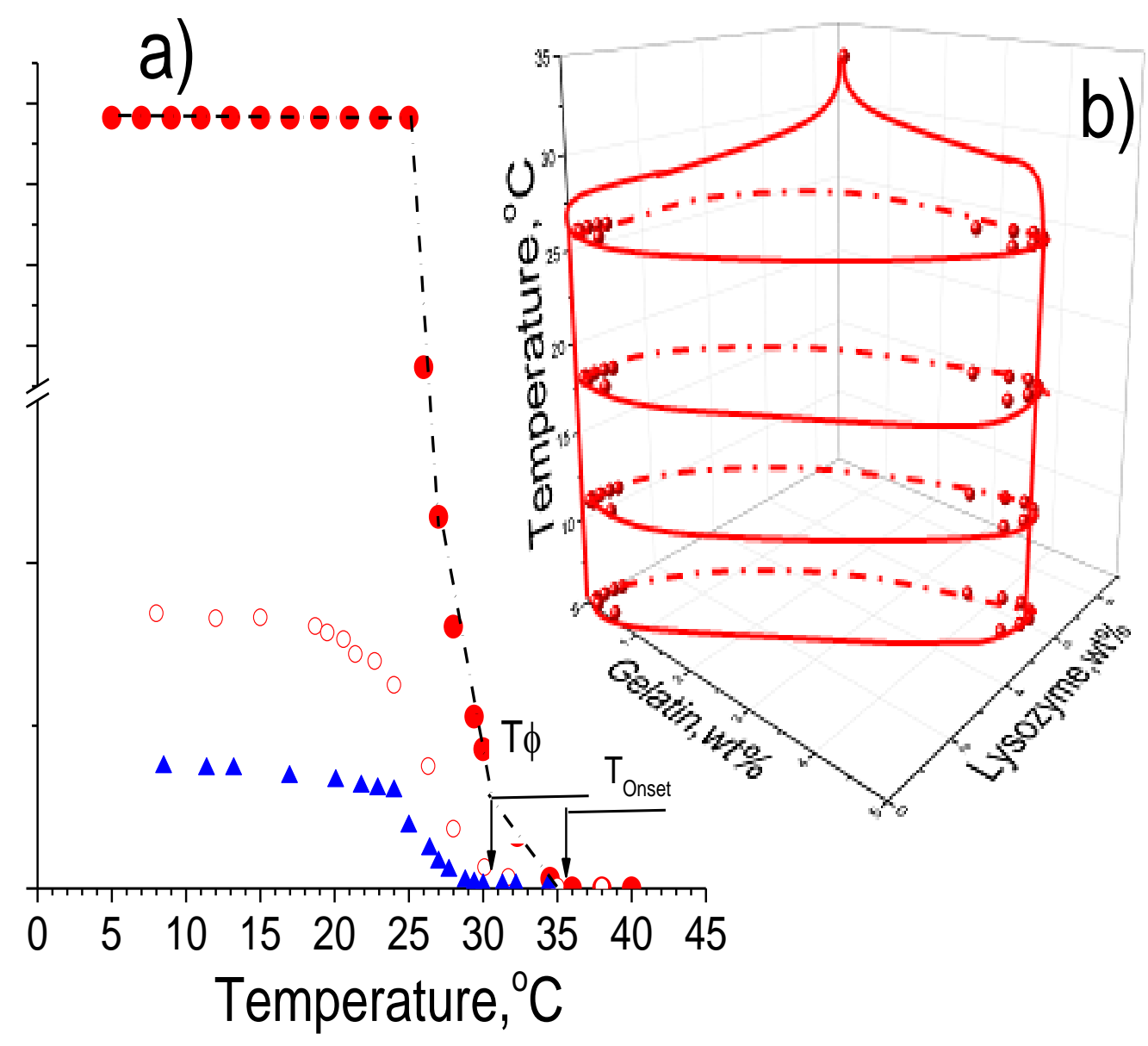

Figure 7. 


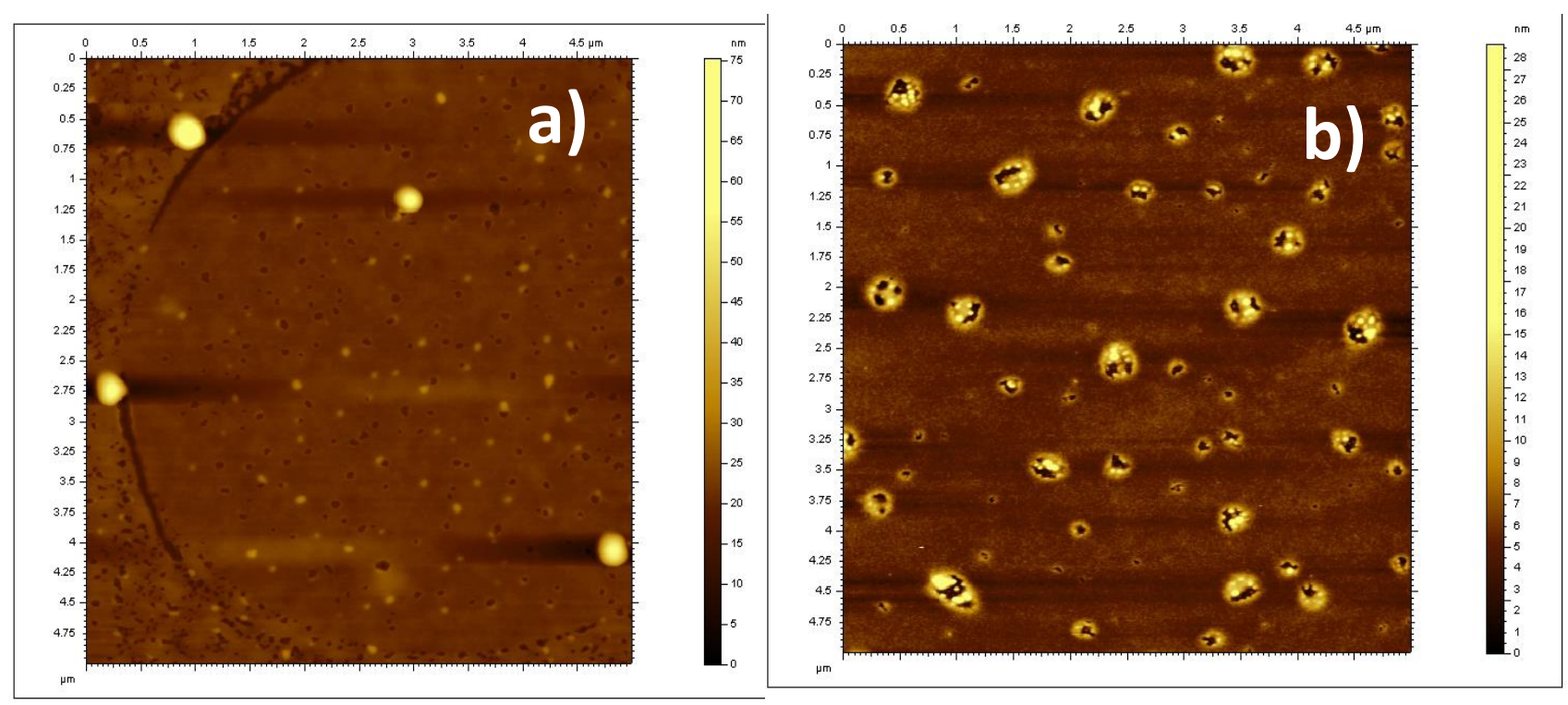

Figure 8. 


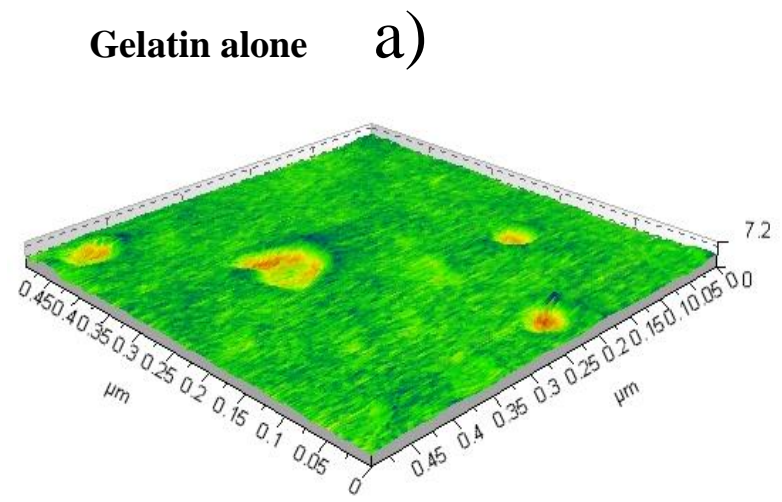

Lys/GelA q=0.5 b)

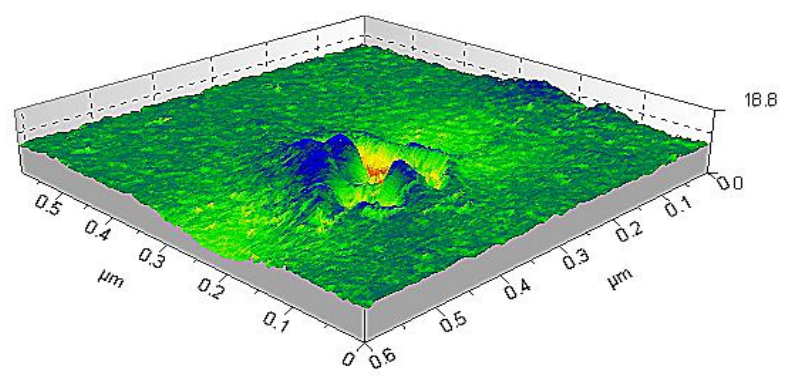

Lys/GelA $\quad$ q=1.0 $\quad$ C)

Lys/GelA q=1.47 d)
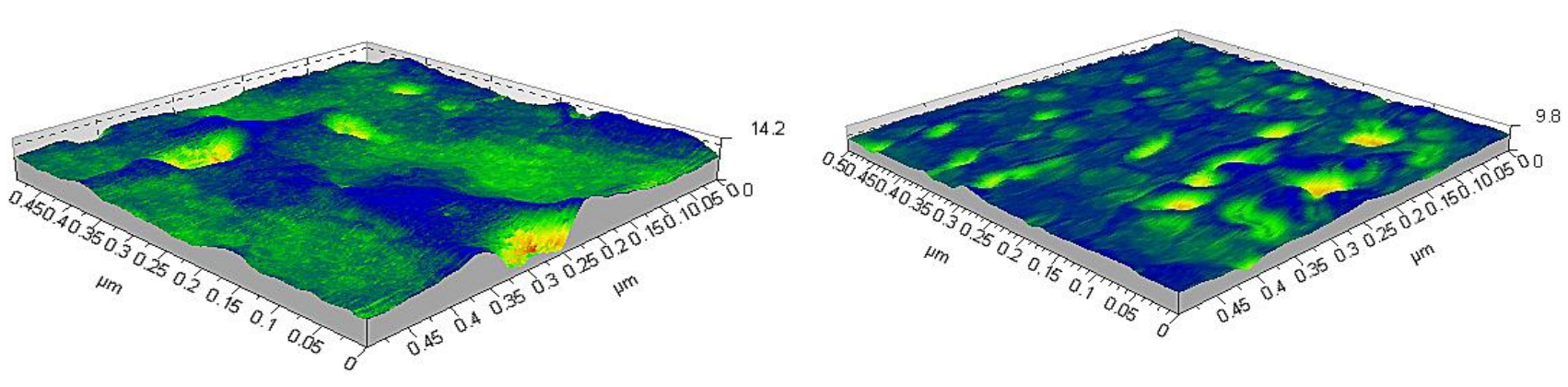

Lys/GelA q=1.47 e)

Lys/GelA q=1.47 f)
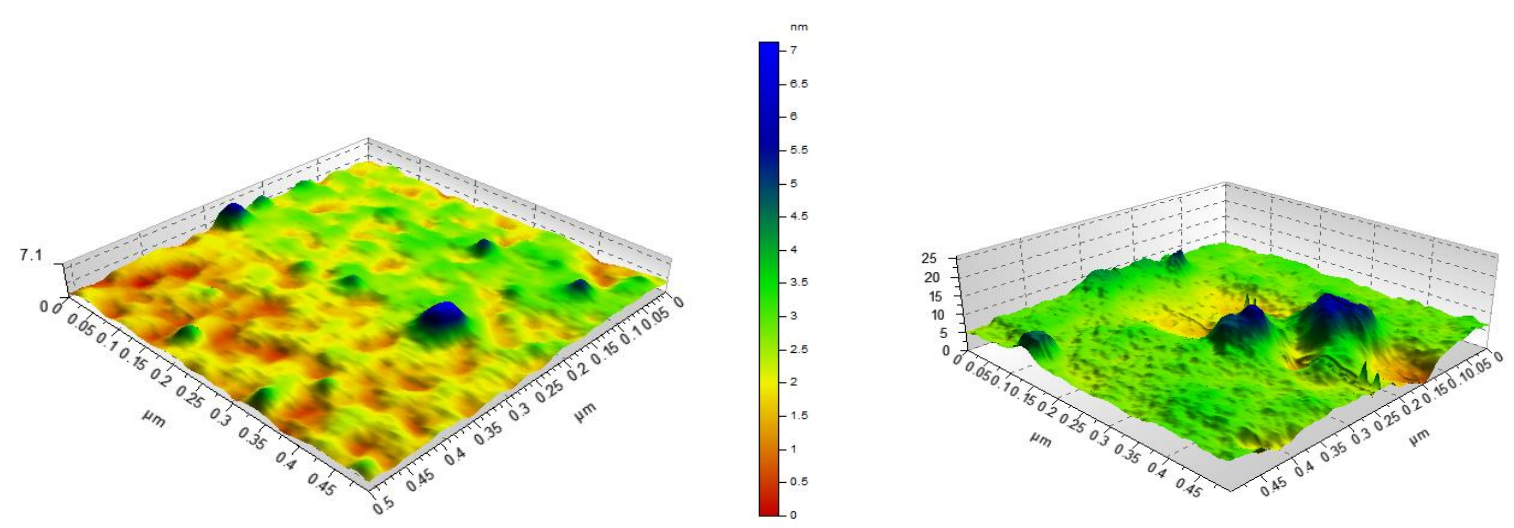

1

Figure 9. 


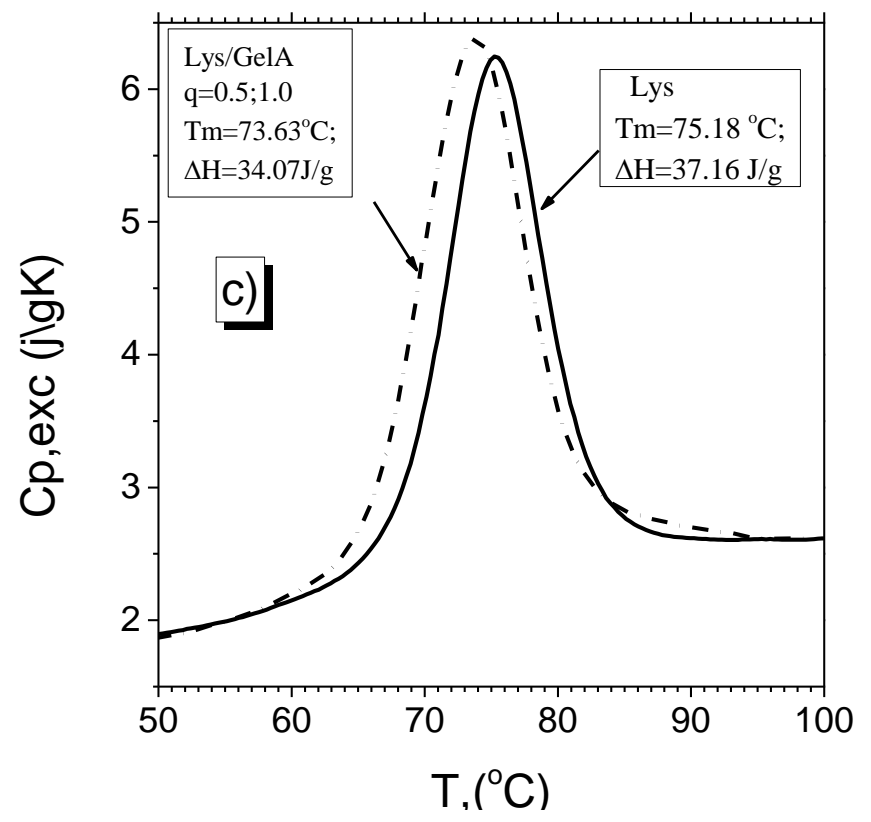

Figure 10 

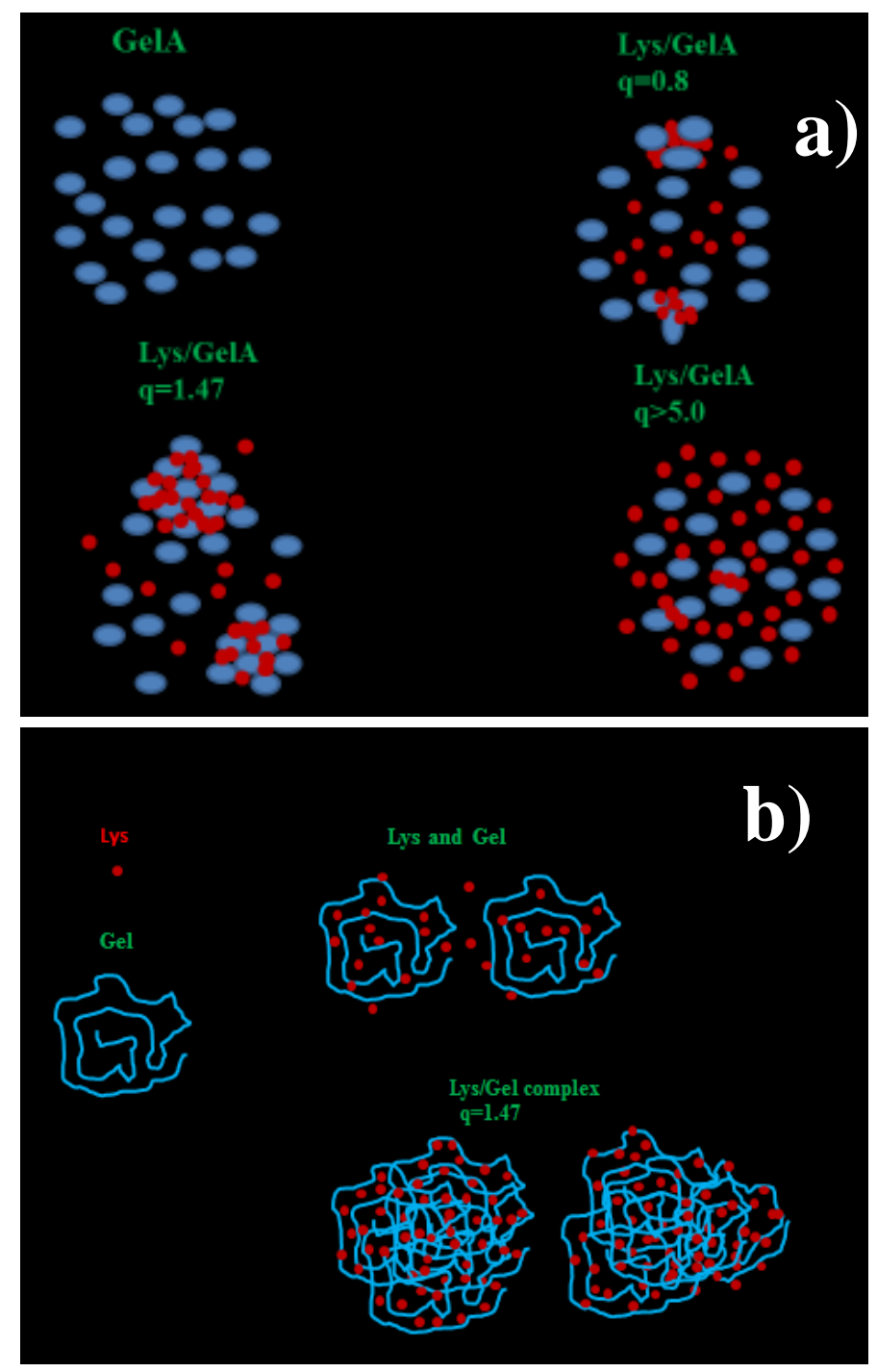

Figure 11 
Graphical file
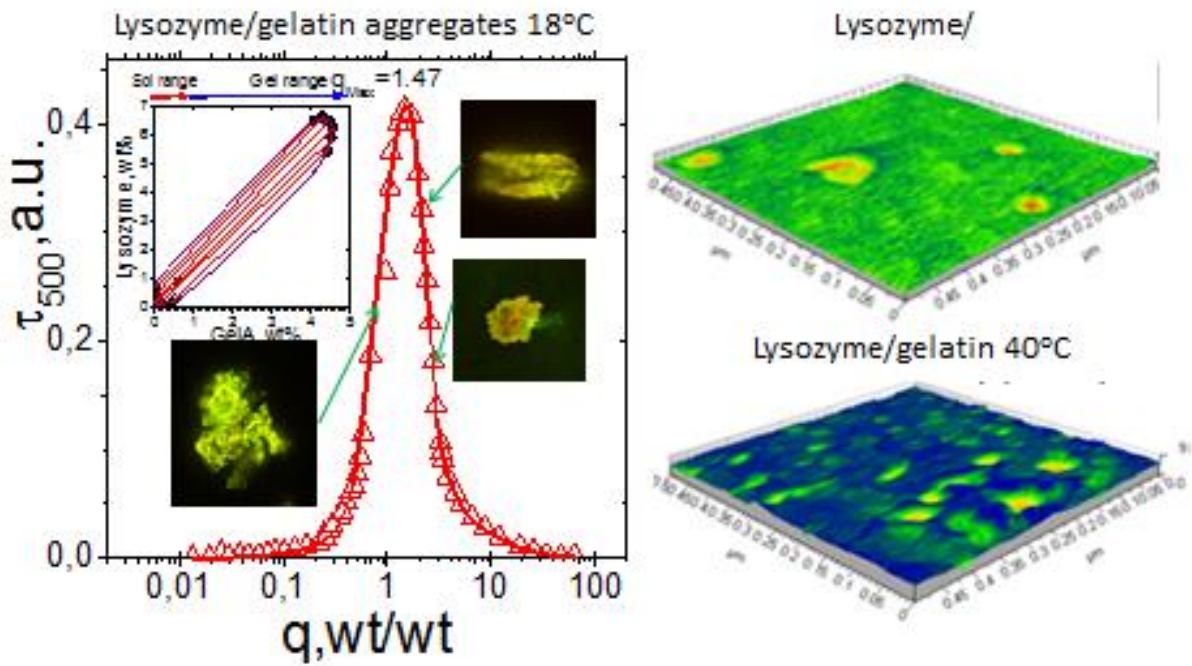